\title{
Title:
}

\section{TuMV triggers stomatal closure but reduces drought tolerance in Arabidopsis}

\section{Authors:}

\section{Carlos Augusto Manacorda1, Gustavo Gudesblat ${ }^{2 a}$, Moira Sutka ${ }^{3 a}$, Sergio Alemano $^{4}$, Franco Peluso ${ }^{5}$, Patricio Oricchio ${ }^{5}$, Irene Baroli ${ }^{3}$, Sebastián Asurmendi ${ }^{1}$}

${ }^{1}$ Instituto de Agrobiotecnología y Biología Molecular (IABIMO), Instituto Nacional de Tecnología Agropecuaria (INTA) and Consejo Nacional de Investigaciones Científicas y Técnicas (CONICET), Los Reseros y Nicolás Repetto, Hurlingham, Buenos Aires, Argentina.

${ }^{2}$ Departamento de Fisiología, Biología Molecular y Celular "Profesor Héctor Maldonado"- Instituto de Biociencias, Biotecnología y Biología Translacional (IB3), Facultad de Ciencias Exactas y Naturales, Universidad de Buenos Aires. Pres. Dr. Raúl Alfonsín S/N, Ciudad Universitaria, 1428EGA, C.A.B.A., Argentina.

${ }^{3}$ Departamento de Biodiversidad y Biología Experimental, Instituto de Biodiversidad, Biología Experimental y Aplicada (IBBEA), Facultad de Ciencias Exactas y Naturales, Universidad de Buenos Aires and Consejo Nacional de Investigaciones Científicas y Técnicas (CONICET), Intendente Güiraldes 2160 - Ciudad Universitaria - C1428EGA, C.A.B.A., Argentina.

${ }^{4}$ Laboratorio de Fisiología Vegetal, Facultad de Ciencias Exactas, Físico-Químicas y Naturales, UNRC. Instituto de Investigaciones Agrobiotecnológicas (INIAB-CONICET), 5800. Río Cuarto, Córdoba, Argentina.

${ }^{5}$ Instituto de Clima y Agua, CIRN, Instituto Nacional de Tecnología Agropecuaria (INTA), Los Reseros y Nicolás Repetto, Hurlingham, Buenos Aires, Argentina.

${ }^{a}$ Gustavo Gudesblat and Moira Sutka should be considered joint second authors.

Keywords: Arabidopsis thaliana, TuMV, stomatal conductance, ABA, ABCG40, drought, RD29A, SA, ORMV.

\section{i) Summary:}

In this work the effects of TuMV infection on stomatal closure and water balance were studied in Arabidopsis. Thermal imaging analyses showed that TuMV-infected plants had consistently higher foliar temperature than mock treated controls. Non-destructive time-course experiments revealed that this differential phenotype was stable during both daytime and nighttime. This effect was due to reduced gas exchange in TuMV-infected plants, as observed through stomatal conductance and stomatal aperture assays in systemic leaves. Measurements of daily water consumption and initial dehydration rate further proved that TuMV infection reduced water loss. Salicylic acid (SA) and abscisic acid (ABA) contents were increased in TuMV-infected plants. In addition, the expression of $A B I 2$, involved in $A B A$ signaling, was enhanced, and $A B C G 40$ (required for ABA transport into guard cells) was highly induced upon TuMV infection. Hypermorfic abi2-1 mutant plants, but no other ABA or SA biosynthetic, signaling or 
degradation mutants tested abolished both stomatal closure and low stomatal conductance phenotypes caused by TuMV. Therefore, not overall ABA levels, but localized differences in ABA import and perception in guard cells, are likely to be responsible for stomatal closure observed under TuMV infection. Plants simultaneously subjected to drought and viral stresses showed higher mortality rates than their mock-inoculated drought stressed counterparts, consistent with down-regulation of drought-responsive gene RD29A, both in short and long day conditions. Our findings indicate that in spite of stomatal closure triggered by TuMV, additional phenomena cause compromised drought tolerance of TuMV-infected Arabidopsis plants.

\section{ii) Significance statement:}

Characterization of the physiological responses controlling plant water management under combined stresses and the genes behind them is important in the current climate change scenario, which poses multifaceted challenges to crops. We found that TUMV infection induced $A B A$ and $S A$ accumulation and stomatal closure in Arabidopsis, alongside with overexpression of ABCG40 (the transporter of ABA to guard cells), whereas the dehydration-responsive gene RD29A was downregulated, concomitantly with increased plant susceptibility to drought stress under infection.

\section{iii) Introduction:}

\section{Viral infections and drought tolerance:}

Phytoviruses are a common cause of agricultural losses worldwide (Loebenstein, 2010). Compatible viral infections often diminish crop value, affecting important traits (Matthews et al., 2002). Therefore, it is widely accepted that viral infections are harmful to the host. However, this paradigm has been challenged in recent years, as more evidence piled up revealing that the outcome of viral infections depends strongly on environmental conditions (Ramegowda and Senthil-Kumar, 2015), an increasingly important issue in view of ongoing global climate change (Bergès et al., 2018; Hily et al., 2016; Grimmer et al., 2012). Under certain environmental circumstances like drought, plant viruses (as reported for some animal viruses (Ryan, 2004)), can be in fact conditional mutualistic partners of plants (Xu et al., 2008; Hily et al., 2016). Therefore, whereas sometimes detrimental to the plant's fitness, viruses could under certain environmental conditions, allow the plant to better tolerate certain abiotic stresses (Carr et al., 2018). These tolerant phenotypes are associated with transpiration rates that are either lower (Xu et al., 2008; Aguilar et al., 2017) or higher (Aguilar et al., 2017; Westwood et al., 2013), due to the fact that the impact of viruses on host stomatal development and function depends on each pathosystem. In compatible interactions, viruses have been shown to alter stomatal development (Hall and Loomis, 1972; Murray et al., 2016; Aguilar et al., 2017) or reduce stomatal aperture (Lindsey and Gudauskas, 1975; Grimmer et al., 2012). However, the molecular mechanisms by which pathogens manipulate stomatal development or aperture are not well understood (Melotto et al., 2017).

\section{Viral infections and plant hormone responses:}

Paramount in the regulation of stomatal opening is the phytohormone abscisic acid ( $A B A)$, involved in the response and tolerance to diverse abiotic stresses, including drought (Vishwakarma et al., 2017; Ma et al., 2018). Salicylic acid (SA) also plays an important role in various plant developmental processes and responses to abiotic and biotic stresses (Raskin, 1992; Vlot et al., 2009; Maruri-López et al., 2019) including stomatal defense (Melotto et al., 2017; Wang et al., 2018; Klessig et al., 2018). ABA has been more often studied in its role in abiotic stress response whereas SA is viewed mainly as acting in biotic (including anti-viral) interactions; however, a growing corpus of evidence points out to a crosstalk between these hormones under both types of stresses (Wang et al., 2018; Alazem and Lin, 2015; Alazem, Kim, et al., 2019; Pasin et al., 2020). Jasmonic acid (JA) is another major plant defense hormone (Pieterse et al., 2012; Alazem and 
Lin, 2015) which, together with SA, orchestrates the defense response to a diverse range of pathogens. Both SA and JA act mainly in an antagonistic way, with SA being a stronger repressor of JA pathway than vice-versa (Vlot et al., 2009; Hickman et al., 2019). JA derivatives were also reported to play a role in stomatal closure (Melotto et al., 2017). The interaction between SA and JA can in turn be modulated by ABA and the cross-talk between ABA and SA is also bidirectional (Vlot et al., 2009). In recent years, the interconnected nature of hormone responses to pathogens has been increasingly emphasized (Alazem and Lin, 2015; Vlot et al., 2009; Klessig et al., 2018; Collum and Culver, 2016).

The hormone profile following viral infections is not homogeneous and depends on the specific pathosystem under study (Collum and Culver, 2016). Several plant-virus interactions display a strong ABA response (Whenham et al., 1986; Alazem and Lin, 2017; Alazem and Lin, 2015) whereas in occasions compatible viral infections can disrupt hormonal balance, resulting in simultaneous induction of ABA and SA pathways, which were traditionally viewed as antagonistic, as in the case of BaMV and CMV infections (Alazem et al., 2014).

Among plant viruses Potyvirus is the largest genus, causing significant losses in a wide range of crops (Revers and García, 2015). Due to their importance, potyviruses are between the most studied phytoviruses and their study covers many aspects of plant virology. However, only a few studies were conducted to date to analyze the impact of potyviral infection under abiotic stress (Revers and García, 2015; Prasch and Sonnewald, 2013). TuMV is one of the best studied viruses of its genus, partially due to its ability of infect the model plant Arabidopsis as well as dozens of species of economic importance (Walsh and Jenner, 2002). TuMV has been shown to interfere with signaling of hormones such as ethylene, ABA and SA (Casteel et al., 2015; Poque et al., 2018; Sánchez et al., 2015) and triggers early accumulation of SA-responsive senescence associated genes (Manacorda et al., 2013).

Here we studied the effect of TuMV infection on water management of Arabidopsis at the level of the stomatal response. TUMV induced partial closure of Arabidopsis stomata as well as increases in SA and ABA content. Genes responsible for $A B A$ biosynthesis and catabolism were downregulated, but genes involved in $A B A$ signaling, and particularly in ABA transport to guard cells, were highly induced by TuMV. ABA, SA and JA loss of function biosynthetic mutants did not abolish the phenotype, whereas abi2-1 hypermorphic ABA signaling mutants exacerbated it to a mild degree. These results indicated that not overall ABA levels, but localized differences in ABA import and perception in guard cells, could influence the closure of stomata under infection. In spite of the shift in hormonal balance, TuMV increased the susceptibility of Arabidopsis plants to drought, in line with the down-regulated transcription of the classic reporter of drought tolerance gene RD29A, both in short day (SD) and long day (LD) conditions. The increased susceptibility to drought of $A$. thaliana plants infected with TuMV is consistent with previously reported findings (Prasch and Sonnewald, 2013) and its occurrence under two different growth conditions in our study points out to a rather robust phenomenon.

\section{Results:}

\section{TuMV induces stomatal closure and lowers water loss in Arabidopsis}

To investigate whether TuMV alters rosette transpiration in Arabidopsis, we inspected TuMV-infected plants non-destructively by infrared (IR) imaging (Costa et al., 2013; Pesti et al., 2019). Figure S1a shows the typical visible phenotypic outcome of TuMV infection (UK1 strain) under SD conditions (Manacorda and Asurmendi, 2018). TuMV-infected plants showed a $\mathrm{T}_{\text {leaf }}$ increase between $0.5-1^{\circ} \mathrm{C}$ relative to the mock-inoculated controls after 2 weeks post-inoculation (DPI) (Figure S1b). It is known that JPN1 and UK1 strains of TuMV cause differential phenotypical and molecular responses in Arabidopsis (Sánchez et al., 2015; Manacorda et al., 2013). Additionally, it has been observed that, as viral infections progress over time, changes occur in several important traits such as viral accumulation, viral-induced accumulation of metabolites and defense-related 
transcripts, and plant morphology, at a rate that is specific for each pathosystem (Alazem et al., 2017; Manacorda et al., 2013; Wang et al., 2011; Bazzini et al., 2011; Manacorda and Asurmendi, 2018). Therefore, the use of the time-course methodology is useful for obtaining a more accurate insight (Alazem et al., 2017; Alazem and Lin, 2015). Taking advantage of the non-destructive nature of IR imaging, we performed a timecourse observation of TuMV-induced $T_{\text {leaf }}$ increase in Arabidopsis for JPN1 and UK1 strains (Figure 1). After 8 DPI both strains caused statistically significant increases in $\mathrm{T}_{\text {leaf }}$ relative to mock treated plants, while no differences were observed between strains throughout the experiment (Figure $1 \mathrm{c}$ ). Because $\mathrm{T}_{\text {leaf }}$ is routinely taken as a proxy of the stomatal conductance $\left(g_{s}\right)$ (Costa et al., 2013; Merlot et al., 2002), and several plantvirus interactions affect both water balance and $g_{s}$ (Xu et al., 2008; El Aou-ouad et al., 2017), we investigated whether TuMV modifies $g_{s}$ in Arabidopsis. We observed that $g_{s}$ values were statistically significantly lower in TuMV-infected samples, without differences between strains (Figure 1d). Therefore, $\mathrm{T}_{\text {leaf }}$ in Arabidopsis negatively correlated with measured $g_{s}$, as expected. Given that both TuMV strains provoked similar IR and $g_{s}$ phenotypes, we selected the UK1 strain to continue our work.

Microscopy imaging observation confirmed that TuMV induced stomatal closure in systemic leaves (Figure 2). The reduction in stomatal aperture was nearly $40 \%$ in average $(p<.0001)$. Whereas stomatal aperture is determined, among other factors, by light intensity, pathogens such as bacteria can trigger stomatal closure under bright daylight (Melotto et al., 2017; Gudesblat et al., 2009), overriding the natural circadian rhythm of stomatal movement. During the night, stomata experience a partial closure as part of this cycle (Caird et al., 2006; Lasceve et al., 1997). We next investigated whether differences in stomatal aperture between treatments were maintained during nighttime (when stomata of mock-inoculated controls are expected to be already closed relatively to daytime). A hydroponically-grown setup optimized for Arabidopsis was employed (Conn et al., 2013). This technique ensures equal access of roots to water and nutrients along the entire experiment, while allowing a more packed scheme for simultaneously imaging several plants without sacrificing pot size (an issue that should be considered when plants are allowed to grow during several weeks). The phenotypes triggered by TuMV could be reproduced in hydroponically-grown plants (Figure S2a). In a time-course experiment between 2-15 DPI, infrared images showed a similar pattern than observed in soilgrown plants (Figure 1c, Figure S2b), both in timing of appearance of significant $\mathrm{T}_{\text {leaf }}$ differences and in their magnitude. Afterwards, infrared images were automatically taken encompassing periods of late daytime, dusk, the entire nighttime, sunrise and early daytime, simulated in the growth chamber (Figure S2c-e). Drops in $\mathrm{T}_{\text {leaf }}$ for all plants during nighttime reflect the temperature drop in the growth chamber. $\mathrm{T}_{\text {leaf }}$ differences between treatments, however, did not change through nighttime, either considering all measurements (Table $\mathrm{S} 1$, interaction treatment:time with $\mathrm{P}=0.11971$ ), or considering periods of day, (dawn, day, dusk and night, Table S2. Interaction treatment:period with $\mathrm{P}=0.73218$ ). Expectedly, in each analysis both time/period and treatment affected $\mathrm{T}_{\text {leaf }}(0.0001<\mathrm{P}<0.01)$ due to lower programmed chamber temperature during nighttime and TuMV treatment, respectively. Although non-statistically significant, we did detect differences in the average $\Delta \mathrm{T}$ between treatments between daytime and nighttime $\left(\Delta \mathrm{T}=0.45^{\circ} \mathrm{C}\right.$ and $\Delta \mathrm{T}=0.31{ }^{\circ} \mathrm{C}$, respectively, Table S3), indicating that at night, differences between treatments are somewhat lower, perhaps due to stomata of TuMV-infected plants being already partially closed during daytime. The expected endogenous behavior of stomata at night with a low peak at midnight and then a slow increase in predawn hours (Caird et al., 2006) could also be detected for both treatments. Therefore, infection with TuMV reduces stomatal aperture throughout the day, during both daytime and nighttime, and does not seem to interfere with the natural circadian rhythm of stomatal movement. Afterwards, taking advantage of the hydoponic setup, we 
carried on experiments of whole-plant daily relative water consumption. Firstly, we verified through gs measurements, that TuMV impaired water loss through stomata in hydroponically-grown plants (Figure S3). Then, we analyzed daily relative water consumption, which was reduced by TuMV (Figure 3a). In addition, experiments of initial dehydration rate of detached rosettes showed that evapo-transpiration rates of rosettes (Figure 3b-c) were reduced by TuMV.

\section{TuMV increases SA and ABA accumulation}

Stomatal conductance is largely controlled by ABA and altered leaf water loss is often indicative of changes in accumulation or sensitivity to ABA (Verslues et al., 2006). Also SA and JA are defense hormones that play a role as regulators of stomatal closure (Melotto et al., 2017). Therefore, we quantified the level of these hormones in Arabidopsis rosette systemic tissue in infected and healthy plants (Figure 4). Under TuMV infection, both ABA and SA levels were greatly increased (205\% and 404\%, respectively; average of two independent experiments) whilst JA levels were not altered by TuMV infection.

\section{ABA-insensitive mutant abi2-1 prevent stomatal closure triggered by TuMV}

Higher concentrations of defense hormones under TuMV infection were somewhat expected because higher levels not only of SA but particularly of $A B A$ are traditionally regarded as underlying stomatal closure (Vishwakarma et al., 2017; Ma et al., 2018; Melotto et al., 2017). To test for the effect of homeostasis of these hormones on the stomatal response to TuMV, we screened a panel of mutants in search of mutations which could abolish the TuMV-induced stomatal closure phenotype (Figure S4). We used $g_{s}$ measurements as a proxy for putative phenotype reversal. Neither mutants in production (sid2), perception (npr1) or degradation (NahG) of SA, nor the aos mutant (which is inactivated in the biosynthesis of JA and its derivatives), nor lox 1-1 (a mutant impaired in the JA-independent oxylipin pathway of stomatal closure response (Montillet et al., 2013)), nor ABA-deficient mutant aba3-1, a severe mutant with only 30-50\% normal ABA levels (Merilo et al., 2017), could revert the phenotype. ABA signaling is also critical in the outcome of the physiological response triggered by this hormone. ABI2 (and other PP2CAs phosphatases) is repressed by ABA, de-repressing in turn OST1 (and other kinases of the SnRK family) to activate SLAC1 anion channels, promoting thus stomatal closure. PP2CA dominant positive/hypermorphic mutants abi2-1 (Koornneef et al., 1984; Leung et al., 1997) cannot be repressed by ABA (Vlad et al., 2009). Therefore OST1 is permanently repressed determining a high degree of stomatal aperture that is insensitive to exogenous application of ABA (Merlot et al., 2002; Merlot et al., 2001). Using the ABA-insensitive abi2-1 signaling hypermorphic mutant the stomatal closure phenotype induced by TuMV was abolished (Figure 5). Moreover, a reproducible but marginally non-significant increase in stomatal aperture (Figure 5b) was detected under TuMV infection of abi2-1 (18\% higher mean stomatal aperture in infected plants and $p=0.076$ for the combined analysis of two independent experiments). Therefore, our results suggest that JA and SA do not participate in TuMV-induced stomatal closure, and that reduced basal $A B A$ levels (such as those present in aba3-1 mutants) are compatible with this phenotype, whereas $A B A$ downstream signaling is essential for it. This finding highlighted the relevance of ABA in stomatal closure mediated by TuMV but posed questions about how ABA homeostasis is modified in TuMV-infected plants resulting in decreased stomatal aperture.

\section{TuMV alters ABA production, catabolism, signaling and transport}


ABA homeostasis during plant stress responses is modulated by its production, inactivation, and transport and is considered to be achieved mainly through transcriptional regulation (Ma et al., 2018; Kushiro et al., 2004). Therefore, we investigated which step(s) of ABA homeostasis is responsible for its over-accumulation under TuMV infection. As ABA metabolism occurs both in shoot and root tissues (Park et al., 2017; Kushiro et al., 2004), aerial and root parts from hydroponically-grown plants were separately harvested to quantify the expression of the most relevant genes related to $A B A$ biosynthesis, degradation, signaling and transport (Figure 6). ABA biosynthetic genes are analyzed in Figure 6a. The rate-limiting step in ABA biosynthesis is catalyzed by the plastid-encoded NCED3 gene (Vishwakarma et al., 2017; Ma et al., 2018), which is the major stress-induced NCED in leaves and, together with NCED2, account for the NCED activity in roots (Tan et al., 2003). Upon TuMV infection, NCED3 was down-regulated in shoots. ABA2 acts downstream of NCED3 in the cytoplasm (Ma et al., 2018) and was also down-regulated by TuMV. Contrarily, AAO3, which catalyzes the last step in ABA biosynthesis (Ma et al., 2018), was up-regulated by TuMV. In roots, NCED3 and ABA2 were not altered by TuMV infection and $\mathrm{AAO}$ showed a level of up-regulation similar to that of shoots. Catabolism plays an important role in ABA homeostasis and a fine-tuned balance of transcriptional activity exists between biosynthetic and degradation genes during stress and recovery (Kushiro et al., 2004). The Arabidopsis P450 genes of the CYP707A family CYP707A1-CYP707A4, encode ABA 8'-hydroxylases that catabolize ABA (Ma et al., 2018; Kushiro et al., 2004). Of these, CYP707A1 and A3 are important mainly in root tissue whereas CYP707A3 is more prominent in leaves (Kushiro et al., 2004). CYP707A1 and A3 were both down-regulated in root and shoot tissues (Figure 6b). Therefore, higher endogenous ABA levels under TuMV infection appear to be due to reduced catabolism compensating for reduced biosynthesis (Figure 6a,b). ABI2 plays a central role acting as a negative regulator of ABA signaling (Merlot et al., 2001; Lim et al., 2015). In addition to its wellknown role in stomatal closure, ABI2 was also reported to have a role in root growth (Leung et al., 1997). We investigated in public gene expression databases $A B I 2$ expression patterns regarding anatomy and perturbations or stresses. An inspection using the efP-Browser tool (Winter et al., 2007) of ThaleMine (Krishnakumar et al., 2015) and Genevestigator V3 (Hruz et al., 2008) showed that ABI2 is mainly expressed in guard cells and roots and is induced by ABA, salt and drought, and senescence (Figure S5), the latter being a process that is greatly accelerated by TuMV-UK1 (Manacorda et al., 2013). Accordingly, we observed an increase in ABI2 expression in roots as well as a weak up-regulation in shoots (Figure 6c).

Besides higher overall rosette ABA concentration triggered by TuMV (Figure 4), augmented ABA transport into guard cells could also be responsible of stomatal closure under infection. ABCG40 is a plasma membranebound ABA transporter mainly expressed in guard cells of aerial tissues but also in primary and lateral roots (Kang et al., 2010; Kuromori et al., 2018). It has very high affinity for ABA and imports it into the guard cells from the surrounding tissues (Park et al., 2017; Ma et al., 2018) where ABA participates in stomatal closure (Kang et al., 2010). To gain insight into ABA transport processes under TuMV infection, we measured ABCG40 expression in roots and shoots. ABCG40 was highly over-expressed in roots (4.5X-linear fold) and shoots (9Xlinear fold) (Figure 6d). The dehydration and pathogen responsive gene RD29A was downregulated by TuMV in shoots (Figure 6e). This result is consistent with RD29A expression reported as downregulated by TuMV and several other biotic stresses including another virus infecting Brassicaceae (Table S4). The results of these qPCR experiments are summarized in Table S4. They are compared with the reported response of these genes to main stresses (perturbations) and tissue and stage of development expression pattern as informed by the online databases of Genevestigator. Table S4 shows that under TuMV infection, the expression of the selected genes for ABA homeostasis and stress response analyzed here, coincide to a great extent with their reported 
responses to $A B A$, including abiotic stresses that typically induce $A B A$ responses, and also to their responses to biotic stresses.

\section{TuMV increases drought susceptibility in Arabidopsis}

Stomatal closure and reduced leaf water loss are well studied phenomena that lead to improved drought tolerance (Lim et al., 2015; Verslues et al., 2006). The overexpression of ABCG40 (Figure 6d), together with stomatal closure (Figure 2) and reduced leaf water loss (Figure 1, Figure S3, Figure 3) all appeared to point out to that outcome under TuMV infection. However, a previous report showed that TuMV increased susceptibility to water deficit in Arabidopsis (Prasch and Sonnewald, 2013). Hence, we performed experiments combining drought and TuMV infection. Soil drying is a technique often used to evaluate plant response to water deficit. In the literature, two main approaches are found: in one of them one plant is used per pot and a treatment/genotype is randomly assigned to each one (Westwood et al., 2013; Xu et al., 2008; Prasch and Sonnewald, 2013), while in the other several plants are placed in the same pot and different treatments are assigned to the plants ( $\mathrm{Xu}$ et al., 2008). This latter approach ensures that roots of plants receiving different treatments, experience the same water deficit stress (Verslues et al., 2006). In particular, plants with decreased stomatal conductance or decreased growth and leaf area (phenotypes which are all present in TuMV-infected plants) are expected to deplete soil water more slowly to avoid low water potential, and may be erroneously designated as more tolerant than controls (Verslues et al., 2006). To determine whether this is indeed the case in our experimental conditions, we firstly tested the one-plant-per-pot approach (Figure S6). It can clearly be seen from Figure $S 6$ that mock-inoculated plants consume available water at a much faster rate than their TuMV-infected counterparts. At the end of the experiment at 42 days after water withholding (DAWW), pots with mock-inoculated plants are still alive and had started reaching a weight plateau, indicative of complete available water depletion in the pot. Meanwhile, some of the TuMV-infected plants had already died because of the advanced stage of viral infection (Figure S6a). This is in line with the more susceptible phenotype detected by (Prasch and Sonnewald, 2013), who used separate pots per plant. Notwithstanding, pots containing TuMV-infected plants had still around $20 \mathrm{~g}$ more of available water. Therefore, we carried out experiments with the two-plant-per-pot approach, assuring that plants receiving different treatments experienced the same water deficit stress (Figure 7). Given the presence of two plants per pot, water was more rapidly removed from soil and at $26 \mathrm{DPI}=\mathrm{DAWW}$, plants receiving each treatment were severely stressed, showing evident leaf turgor loss (Figure 7a). After re-watering however, $100 \%$ of mock-inoculated plants survived but only $9 \%$ of TuMV-infected plants recovered (Figure $7 b ; \chi^{2}=7.3 e-11$, Table 1). To test for the robustness of the phenomenon and to facilitate the comparison with experimental conditions reported for the combined stress of drought + TuMV (Prasch and Sonnewald, 2013), we repeated the experiment but in LD conditions and compared pot weight loss and survival rates under different photoperiod conditions and treatments (Figure 7c-d, Table 1). As expected, soil drying was much faster in LD conditions (Figure 7c-d), to the extent that this standard photoperiod is perhaps not the most suitable for our pathosystem to study in detail the low water potential response (Verslues et al., 2006). Nonetheless, we found that TuMV increased drought susceptibility also in LD experiments $\left(\chi^{2}=0.02\right.$, Table 1$)$. These results are in line with reduced expression of RD29A gene in systemic tissues from well-watered TuMV-infected plants in both SD and LD conditions (Figure 6e, Figure 7e). Of note, previous results (Manacorda et al., 2013) studying TuMV infection in well-watered Arabidopsis under similar LD growing conditions, allowed plants to survive for more than 21 DPI, indicating that TuMV alone is not responsible for premature plant death observed here. Therefore, the two- 
plants-per-pot approach, which is appropriate to study the combined stresses of TuMV infection + drought, showed that despite stomatal closure and reduced relative evapo-transpiration and water consumption, TuMV-infected plants are more susceptible to drought than mock-inoculated controls. The observed reduction in RD29A expression under well-watered conditions, both in SD and LD photoperiods, is in line with the reported expression of this gene under pathogen attack and SA treatments (when it is down-regulated, Table S4) and contrary to its expression under water stress only (when it is up-regulated (Narusaka et al., 2003)). We confirmed that SA treatment alone downregulates RD29A (Figure S7).

\section{ORMV also triggers a hot-leaf phenotype in Arabidopsis}

$\mathrm{T}_{\text {leaf }}$ increase is not a universal phenomenon arising from compatible viral infections. For example, tobacco plants susceptible to TMV (a virus belonging to the Tobamoviridae family unrelated to TuMV) failed to accumulate SA and did not increase $\mathrm{T}_{\text {leaf }}$ relative to healthy controls (Chaerle et al., 1999). Therefore, we tested whether Arabidopsis infected with ORMV (a Tobamoviridae member capable of establishing a compatible infection in this host) showed a hot-leaf phenotype. Figure S8 shows that this is indeed the case.

\section{Discussion:}

\section{Plant viruses and its impact on stomata}

TuMV induced an average $\mathrm{T}_{\text {leaf }}$ increase of $0.5-1{ }^{\circ} \mathrm{C}$ (Figures S1-S2 and Figure 1), which is within the reported range for other virus-infected plants (Aguilar et al., 2017; Chaerle et al., 2006). As expected, TuMV decreased $g_{s}$ (Figures 1d and Figure S3) in line with reduced stomatal aperture (Figure 2) and lowered relative daily water loss and initial dehydration rate (Figure 3). This characterization of the stomatal response of Arabidopsis to TuMV adds another piece of information about this well-studied pathosystem.

High relative $\mathrm{T}_{\text {leaf }}$ profile or/and diminished $g_{s}$ or shoot water loss under viral infection have been reported previously for other pathosystems (Aguilar et al., 2017; Xu et al., 2008; Murray et al., 2016). This is, however, not a universal phenomenon; in the case of Arabidopsis, there are reports describing enhanced water loss and/or decreased $\mathrm{T}_{\text {leaf }}$ in virus-infected plants (Westwood et al., 2013; Aguilar et al., 2017) concomitantly with enhanced drought tolerance, a pattern opposite to what we have found for the Arabidopsis-TuMV interaction (see below for further discussion). Our findings are however in line with those of (Guo et al., 2005), who detected a sharp decrease in $g_{s}$ in TuMV-infected Brassica juncea plants (a member of the Brassicaceae family related to Arabidopsis). We also found an increase in $\mathrm{T}_{\text {leaf }}$ in ORMV-infected Arabidopsis plants (Figure S8), whereas (Chaerle et al., 1999) did not find any $T_{\text {leaf }}$ differences when infecting tobacco plants with TMV, a virus related to ORMV. These contrasting findings highlight the need to study in detail each plant-virus interaction to characterize the impact that each virus may have on stomatal function.

\section{TuMV increased SA and ABA accumulation but stomatal closure depends on ABA perception and not wild- type basal levels}

ABA, SA and JA are plant hormones involved in antiviral defense (Klessig et al., 2018; Vlot et al., 2009; Alazem and Lin, 2015; Alazem and Lin, 2017; Lewsey and Palukaitis, 2010) and drought response (Wang et al., 2018; Raskin, 1992; Okuma et al., 2014) and a recent and growing corpus of research is making links between these two roles (Li et al., 2012; Aguilar et al., 2017). Interestingly, a synergistic interaction between ABA and SA was proposed for at least some aspects of antiviral responses (Alazem and Lin, 2015). JA levels were mostly 
unchanged in response to TuMV infection (Figure 4), a result previously found in this pathosystem (Casteel et al. , 2015). On the other hand, both ABA and SA levels were increased (Figure 4). SA synthesis/signaling and the SA-dependent defense are important to limit viral infection and spread (Rodriguez et al., 2014; Conti et al., 2012; Collum and Culver, 2016). However, the role played by SA in the Arabidopsis-TuMV interaction is not yet fully understood: on the one hand the use of transgenic plants overexpressing NahG with reduced levels of SA (Brenya et al., 2016) led to the conclusion that endogenous SA did not affect resistance to TuMV (at least from the point of view of visual symptom development). On the other hand, previous studies using similar NahG transgenic plants found that SA plays a role in ROS generation after TuMV infection (Manacorda et al., 2013). The same study found that a set of SA-responsive genes related to defense and senescence was highly induced from early stages of TuMV infection with the UK1 strain. Additionally, (Poque et al., 2018) showed that the interaction between TuMV protein HC-Pro and a host SA-binding protein reduced SA signaling capability and increased susceptibility to TuMV, suggesting that the SA pathway is an important obstacle to TuMV spread. Our findings here are in line with previous studies that showed an increase in SA levels after TuMV infection in Arabidopsis (Poque et al., 2018; Casteel et al., 2015). However, increased levels of SA are unlikely to be behind the stomatal closure triggered by TuMV, as mutations affecting SA biosynthesis or perception, or decreasing of SA levels through NahG overexpression failed to prevent a reduction in $g_{s}$ (Figure S4). Perhaps less unexpectedly due to unchanged JA levels in response to TuMV infection, oxylipins pathways mutants (either related with the JA biosynthetic pathway-aos- or not-lox1-1) also failed to abolish the phenotype triggered by TuMV. Interestingly, aba3-1 plants also failed to suppress the TuMV- induced decrease in $g_{s}$, demonstrating that reduced endogenous basal ABA levels alone are not enough to hinder this response. The fact that $a b a 3-1$ mutants are still capable of closing stomata despite their low endogenous ABA levels in an ABA-dependent process could be explained on the basis that not only the minimum $A B A$ threshold necessary to trigger stomatal closure is not yet determined, but also because it is proposed that the threshold of $A B A$ to initiate downstream processes is lower in the guard cells (Merilo et al., 2017). ABA-insensitive dominant positive/hypermorphic abi2-1 mutant plants abolished stomatal closure and low $g_{s}$ under TuMV infection (Figure 5), proving that these phenotypes are dependent on ABA in general and ABA sensitivity in particular. In WT plants, ABI2 represses OST1/SnRK2.6, which in turn acts activating SLAC1 anion channels that trigger stomatal closure in guard cells (Lee et al., 2013). In abi2-1 mutants, OST1 is permanently repressed determining a high degree of stomatal aperture (Merlot et al., 2002; Merlot et al., 2001). Moreover, stomatal aperture is further promoted in these mutants because PP2CA proteins can also directly repress SLAC1 anion channels (Rodriguez et al., 2019). To sum up, TuMV-triggered stomatal closure is dependent on ABA signaling by PP2CAs (Figure 5) but not on other well-known hormones or metabolites capable of causing stomatal closure and this phenotype does not require WT basal rosette ABA levels despite occurring concomitantly with a rise in endogenous ABA levels (Figure 4).

\section{TuMV impacts on ABA metabolism and transport}

The understanding of the important role that $A B A$ response has in the context of viral infection is gaining momentum (Alazem and Lin, 2017; Pasin et al., 2020). For example, ABA has been proposed to be at the core of extreme resistance mechanisms following soybean infection by the potyvirus Soybean Mosaic Virus (SMV) (Alazem et al., 2018; Alazem, Widyasari, et al., 2019). Here, we performed transcriptomic qPCR experiments to understand the origin of increased overall rosette $A B A$ levels under infection and its putative effects on pathogen response as well as the relative independence of stomatal closure on absolute endogenous $A B A$ 
levels. Increased levels of ABA in shoots were detected in spite of NCED3 and ABA2 down-regulation in shoots (Figure 6a). The slight relative up-regulation of AAO3 in roots and shoots could account for a faster processing of remaining $A B A$-aldehyde intermediate, but this conclusion is not guaranteed since it has been shown that AAO3 mRNA could be strongly induced without downstream higher protein level or enzymatic activity (Ma et al., 2018). Interestingly, AAO3 (but not NCED3 or ABA2) induction was also reported in Arabidopsis infected with BaMV (Alazem et al., 2014). NCED3 and ABA2 were found to be positive regulators of BaMV accumulation and $\mathrm{AAO} 3$ and several $\mathrm{ABA}$ signaling downstream of it (including the hypermorphic abi1-1 that is functionally equivalent to abi2-1 used here) had the inverse role. Therefore, NCED3 and ABA2 downregulation and $A A O 3$ and $A B I 2$ overaccumulation detected in our study (Figure 6) are most probably part of a defense response mounted by the host. (Alazem et al., 2014) found that both CMV and BaMV triggered ABA accumulation but also upregulated the mRNA levels of several genes from the $S A$ and $A B A$ pathways, therefore concluding that both CMV and BaMV infection disrupt ABA-SA antagonism. Our results support their suggestion that the increase of $A B A$ and upregulation of the ABA and SA pathways may be common features of RNA viruses infection (Alazem et al., 2014). Additionally, down-regulation of P450 cytochromes that degrade ABA (Figure 6b) could be compensating for the reduced biosynthesis, also taking into account that in roots NCED3 and ABA2 have unchanged transcriptional levels but P450 cytochromes are also downregulated there and $A B A$ transport throughout the plant is a well-established phenomenon. Further studies should complement these findings by analyzing ABA content in shoots and roots separately. This molecular phenotype is in agreement with the augmented drought susceptibility detected (Figure 7) since it was recently suggested that drought-induced ABA synthesis occurs in shoot vasculature (Park et al., 2017) and in Arabidopsis, NCED3 is considered as a dominating contributor to ABA production under water deficit, with other NCEDs, as well as other enzymes within ABA synthesis pathway playing a relatively minor role (Ma et al., 2018). NCED gene was found to be overexpressed in response to drought stress in several plant species including Arabidopsis (Vishwakarma et al., 2017). Therefore, NCED3 down-regulation by TuMV goes in the opposite direction of water stress tolerance. NCED3 is a chloroplastic gene and its transcription downregulation could originate from its subcellular localization and the early onset of senescence triggered by TuMV (Manacorda et al., 2013). Recently, more attention was given to chloroplast function impairment during viral infections, as well as the role this organelle has in antiviral defense (Zhao et al., 2016; Bhattacharyya and Chakraborty, 2018). Transcriptomic studies of potyviral infections found that plastid genes and genes involved in chloroplast functions were preferentially underexpressed, whereas senescence-associated genes (SAGs) including several defense- and stress-associated genes, were overexpressed (Revers and García, 2015). Moreover, the majority of Potyviral proteins have the capability of physically interacting with host chloroplastic proteins (Revers and García, 2015) and TuMV can alter chloroplast morphology (Zhao et al., 2016). TuMV UK1 strongly induces the SAG ORE1 transcription and early chlorophyll loss in systemic Arabidopsis and $B$. juncea leaves (Manacorda et al., 2013). ORE1 is a negative regulator of G2-like transcription factors, which are important in chloroplast development and maintenance (Rauf et al., 2013). In line with this, it was shown that TuMV-infected B. juncea plants showed a noticeable decrease in total chlorophyll content after 2 weeks of infection (Guo et al., 2005).

Not only overall $A B A$ levels but also $A B A$ distribution within the plant is important to trigger physiological responses. $A B C G 40$ is the only bona fide $A B A$ importer into guard cells reported to date (Park et al., 2017; Kuromori et al., 2018). Contrary to ABA exporters from guard cells like ABCG25, in shoots ABCG40 is mostly expressed in guard cells (Kuromori et al., 2010; Kuromori et al., 2018; Kang et al., 2010). Although ABA can be 
synthesized in guard cells to allow for rapid stomatal responses to atmospheric factors, long-term stomatal stress responses appear to depend more on ABA biosynthesized in phloem companion cells (Merilo et al., 2015; Kuromori et al., 2018). Therefore, increased levels of ABCG40 mRNA (Figure 6d) could contribute a major part of the ABA pool in guard cells. Additionally, although contributing to a minor part to the $A B A$ pool in shoots, CYP707A1 can down-regulate ABA content in guard cells via its preferential expression there, thus influencing stomatal closure (Kuromori et al., 2018). CYP707A1 and CYP707A3 were down-regulated both in roots and shoots (Figure 6b). Accordingly, increased ABA transport to guard cells and reduced catabolism could explain stomatal behavior under TuMV infection even in aba3-1 mutants with lower overall shoot ABA levels (Figure S4). Down-regulation of CYP707A genes were unexpected in the light of the augmented ABA concentration detected in TuMV-infected rosettes (Figure 4) because CYP707A genes are induced by high endogenous ABA, whose levels contribute to limit under stress (Kushiro et al., 2004). CYP707As downregulation detected here are also the contrary pattern of what is generally detected in plants under water stress (Ma et al., 2018; Kushiro et al., 2004), where these cytochromes control the excessive level of ABA, further indicating that TuMV-infected plants are ill-prepared to stand drought. PP2CAs including ABI1 and ABI2 are required for $A B A$ signaling in Arabidopsis and generally function as negative regulators of the $A B A$ response (Lee et al., 2013; Merlot et al., 2001). ABI2 has been reported as transcriptionally up-regulated by ABA and abiotic stresses (Figure S5c-d, Table S4), and regarding pathogen response, at least some PP2CA members are important in determining bacterial resistance via stomatal closure through their interaction with ABA receptors (Lim and Lee, 2015). ABI2 mRNA relative levels were marginally higher in TuMV-infected shoots (Figure $6 \mathrm{c}$ ). This effect, in fact, could be under estimated by the whole-shoot RNA extraction, that reflects the effect of overall shoot $A B A$ levels. Since in shoots guard cells are the primary site of $A B I 2$ expression (Figure S5a), higher ABA levels determined by increased ABCG40 and decreased CYP707As transcription (Figure 6b,d) were expected to determine high local mRNA ABI2 levels (Figure S5c). The strong overexpression of the highaffinity importer ABCG40 in shoots (+9.5 fold relative to control plants) suggests that ABA is being massively imported from surrounding tissues into guard cells. Nevertheless, higher ABA levels in guard cells must lead to increased local ABI2 protein repression: ABA perception through PYR/PYL/RCAR receptors leads to interaction with and inactivation of PP2CAs like ABI2 (Rodriguez et al., 2019), thus promoting the detected stomatal closure (Figure 2). In this context, it is interesting to note that stomatal aperture assays on abi2-1 hypermorphic mutants (Figure 5b) although showed no statistical differences between treatments, yielded similar results in two independent experiments, with an average stomatal aperture increase of $18 \%$ in TuMVinfected plants instead of a reduction as detected in infected WT plants (Figure 2). Accordingly $g_{s}$ measurements, carried on in plants of additional independent experiments (Figure 5a), was detected to be slightly higher in TuMV-infected vs. healthy abi2-1 mutants, an opposite pattern regarding WT results (Figure S3, Figure 3). We propose that in these mutants, the local increase in ABA in guard cells under infection leads to an expected increase in $A B I 2$ mRNA, which is translated into additional mutant $A B I 2$ protein, which is in turn incapable of down-regulation through PYR/PYL/RCAR ABA receptors, further promoting stomatal aperture.

Transcriptomic profile of ABA metabolic pathway genes under TuMV marked induced senescence, pathogen response and increased drought susceptibility

Table S4 compares our transcriptomic results for the selected ABA metabolic pathway genes with reported data retrieved from Genevestigator V3 (Hruz et al., 2008) for most important perturbations (stresses), 
tissues/cell lines (anatomy) and developmental expression pattern in Arabidopsis. Except for RD29A, the expression pattern of all genes analyzed under TuMV infection was the same as reported for senescent tissues (Table S4, Figure 6). This was expected since it has been reported that TuMV induces the early onset of senescence in Arabidopsis (Manacorda et al., 2013; Sánchez et al., 2015). The majority of the genes analyzed here (Figure 6) are markedly altered by biotic stresses, particularly biotrophic pathogens that typically trigger a SA-dependent response (Li et al., 2019) like $P$. syringae, but also $P$. parasitica and $M$. incognita, in the same direction of regulation as triggered by TuMV (up-or down-regulation). Most of these genes were also highly expressed in roots and guard cells, as expected, as they are places where ABA plays important physiological roles. Interestingly, $A B C G 40$ expression had been previously detected in roots and its expression increased mainly under pathogen attack, as it did here (Figure 6d). As for RD29A expression, its consistent downregulation by TuMV both under SD and LD conditions (Figure 6e, Figure 7e) shows a pattern that is the opposite of what was reported under drought conditions (Wang et al., 2018; Yamaguchi-Shinozaki and Shinozaki, 1994).

\section{RD29A is downregulated by SA and viruses}

RD29A is routinely used as an indicator of stress response, since it was originally reported to be induced by ABA treatment but also by abiotic stresses such as salt and drought, for which promoter elements exist that can respond independently from ABA (Yamaguchi-Shinozaki and Shinozaki, 1994). Interestingly, (Westwood et al. , 2013) confirmed the up-regulation of RD29A gene under ABA treatment but also found that RD29A was repressed in Arabidopsis plants infected with Fny-CMV in both well-watered and drought-stressed conditions. These authors found no changes in ABA levels following infection. Remarkably, data mining using Genevestigator revealed that previous reports showed that viral infections triggering an SA response repress RD29A both in the case of TuMV (Yang et al., 2007) and CaLCuV (Ascencio-lbáñez et al., 2008) and that SA treatment alone represses RD29A in plantlets and mature rosettes (Table S4), a result we confirmed here (Figure S7). Noteworthy, the strength of RD29A repression appear to be linked to the duration of the SA treatment: when a single SA spray is used, RD29A is significantly but slightly repressed at 3-6 h post treatment but this effect fades away at $24 \mathrm{~h}$ or later (Figure S7, Table S4). On the contrary, a sustained SA treatment such as a 1-day submersion of Arabidopsis roots in SA solution triggers a strong repression of RD29A (-13.6 X linear fold change, Table S4). This kind of sustained response is more likely to be occurring in our TuMV-infected plants at 12 DPI, when infected plants have a near $400 \%$ increase of SA levels (Figure 4). Indeed, previous reports showed that a transcriptomic and biochemical systemic response that is typically SA-dependent is triggered by TuMV (UK1) as early as 4 DPI, through 21 DPI (Manacorda et al., 2013). The fact that TuMVinduced RD29A repression in LD conditions is severely accentuated from 10 to 16 DPI, further supports that view (Figure 7e). Moreover (Ascencio-lbáñez et al., 2008), showed that CaLCuV (a virus that triggers a pathogen response via the salicylic acid pathway) highly repressed RD29A at 12 DPI under SD conditions. Additionally, previous reports using npr1, sni1 and brca2a single, double or triple mutants (Durrant et al., 2007; Wang et al., 2010) demonstrated that RD29A depends on these SA-responsive genes for its normal transcriptional levels. The SA response of RD29A was even reversed in some of these mutant's combinations. Therefore, RD29A appears to be not only an indicator of ABA-mediated abiotic stress response (when it is overexpressed) but also of biotic stress and particularly, viral infections and SA treatment (when it is underexpressed) (Table S4, (Westwood et al., 2013; Ascencio-lbáñez et al., 2008; Yang et al., 2007), this study: Figure 6e, Figure 7e, Figure S7). This response is not bound to lower ABA levels ((Westwood et al., 2013), this 
study: Figure 4) and could arise from the independently acting cis-elements described in its promoter region (Yamaguchi-Shinozaki and Shinozaki, 1994). Here, we detected both ABA and SA increased levels (Figure 4). These hormones of opposite effect on RD29A expression resulted in a pattern of expression that is not the same as reported after ABA increase only, but should not be unexpected: when confronted to a combination of stresses, plants mount unique physiological, molecular, and biochemical responses that is not just an additive effect of the responses deployed when the stresses are imposed separately (Mahalingam, 2015). In fact, regarding specifically dual stress effects on RD29A, a previous work studied RD29A expression under combined $\mathrm{ABA}+\mathrm{NaCl}$ treatments and found that not only the magnitude of RD29A expression but also its temporal dynamics were altered relative to the response recorded after single stimulus, despite $\mathrm{NaCl}$ being known to trigger ABA itself (Lee et al., 2016). Accordingly, despite enhanced ABA levels during TuMV infection, RD29A expression would be ultimately determined from the complex weighting between ABA and SA in the regulation of this gene. Plants that cannot induce RD29A in the presence of ABA are also more susceptible to $\mathrm{NaCl}$ or mannitol (Jeong et al., 2018) and we found here that TuMV-infected plants were more susceptible to drought stress (Figure 7).

\section{Decreased drought tolerance under TuMV infection: putative physiological and molecular causes}

TuMV induced stomatal closure (Figure 2) and reduced $g_{s}$ (Figure S3, Figure 3) concomitantly with reduced drought tolerance (Figure 7a,b, Table 1). These apparently contrasting phenomena could have their explanation in the broader role that SA and particularly ABA have in regulating water stress in plants and in the spatial distribution of ABA (Wang et al., 2018; Kuromori et al., 2018; Yoshida et al., 2019). The strong induction of high-affinity ABCG40 (Figure 6d) under TuMV could indicate that an important fraction of additional ABA accumulated could be translocated to specific cell types such as guard cells, leaving less hormone available to other physiological functions that cope with stress. A recent review (Yoshida et al., 2019) summarizing $A B A$ roles under non-stress conditions specifically noted that the uneven distribution of $A B A$ concentration throughout the leaf due to the action of transporters, catalytic enzymes and ABA mobility can explain stomatal closure under well-watered conditions and that this effect could be obscured by dilution in whole-leaf ABA measurements. The authors also pointed out that measuring ABA with cellular resolution remains an important and outstanding task for the future. Physiological $A B A$ functions extend well beyond stomatal closure, coordinating all the various aspects of drought response (Verslues et al., 2006) including water penetration and hydraulic control, both in leaves and roots to systemically cope with water stress (Kuromori et al., 2018; Yoshida et al., 2019). In roots, ABA regulates not only hydraulic conductance (possibly by regulating aquaporin activity (Kuromori et al., 2018)) but also primary growth, suberization and hydrotropism (Yoshida et al., 2019) and it can inhibit lateral root formation under $\mathrm{NaCl}$ stress (Duan et al., 2013). The modification of these traits can obviously have an impact in water stress tolerance. Interestingly, the latter authors found that lateral root inhibition occurs in root endodermis cells, a cell line where $\mathrm{NaCl}$ and other stresses reportedly induced ABCG40 and ABI2 (Figure S5, Table S4), whose transcripts we detected highly overexpressed in roots under TuMV infection (Figure 6c,d). Noteworthy, both ABCG40 and ABI2 were reported to be highly expressed not only in guard cells, a feature that can explain that an over-expression would determine stomatal closure (Figure S3, Figure 3, Figure 6c,d, shoot analyses), but also in root endodermis and root cortex and lateral root cap, where PP2CAs like ABI2 were recently found to be involved in root patterning under stress (Rodriguez et al., 2019; Dietrich et al., 2017; Orman-Ligeza et al., 2018). 
Therefore, increased reported ABCG40 levels in roots occurs in cell lines that are highly responsive to $A B A$ and leads to important morphological changes, pointing out to a possible additional role for this $A B A$ transporter in root tissue besides its role in shoots (Kuromori et al., 2018). As TuMV infection induced root overexpression of $A B I 2$ and $A B C G 40$ genes (Figure $6 c, d$ ), we speculate that TuMV induces root re-patterning. Plant viruses can disturb water management at a whole-organism scale, simultaneously modifying water loss rate through stomata and water intake from the roots (El Aou-ouad et al., 2017). The importance of root-based events in plant-virus interactions has been pointed out already and future work should focus on assessing relevant root parameters under viral infections (Westwood et al., 2013).

Additionally, viral factors interfering with stress-responsive genes can hamper adaptive drought responses, such as the down-regulation of RD29A detected here (Figure 6e, Figure 7e), or vice-versa: (Prasch and Sonnewald, 2013) found that the transcriptomic phenotype of TuMV-infected plants is different from the one that is triggered by drought or by the combination of both stresses, and proposed that specific combinations of abiotic or biotic stress act synergistically or antagonistically, respectively. These authors found also that transcripts related to defense genes were differently activated under the combination of TuMV + drought, and signaling components were reduced under multiparallel stress, probably deactivating TuMV-specific signaling networks, leading thus to increased susceptibility of plants under the combined stress.

Here, we concluded that TuMV reduced water loss through stomata in Arabidopsis but enhanced drought susceptibility. We found that stomatal closure correlated with enhanced total rosette ABA levels and highly increased transcription levels of $A B A$ importer to guard cells $A B C G 40$. Therefore, this work reinforces and expands previous findings concerning Arabidopsis-TuMV interaction regarding combined stresses (Prasch and Sonnewald, 2013) and hormone response (Manacorda et al., 2013; Sánchez et al., 2015; Casteel et al., 2015; Poque et al., 2018). Whereas recent reports studying combinations of virus plus drought stresses have pointed out to an increased tolerance to drought triggered by diverse viruses (Westwood et al., 2013; Xu et al., 2008; Aguilar et al., 2017), the only previous report using Arabidopsis infected with TuMV (Prasch and Sonnewald, 2013) found increased susceptibility, consistent with the present work. All these reports, however, used the one-plant-per-pot approach, which has the shortcomings pointed by (Verslues et al., 2006) regarding the assumption of equal root stress. Even (Xu et al., 2008), who placed plants receiving different inoculation treatments (mock- or virus-inoculated) in the same trays, placed plants of each treatment group close together, thus creating a higher distance between roots of plants receiving different inoculation treatments. We chose to follow the approach of two plants per pot with "recovery after rewatering" proposed by (Verslues et al. , 2006) that allowed to quantify differences in survival rates between treatments with a simple $\chi^{2}$ test (Table 1). Whereas our work in any way invalidates those previous reports, we used an alternative methodological approach to study the combination of stresses that deal with challenges arising from differential stomatal aperture, root architecture and other traits affected by plant viruses. Apart from that, this work further reinforces the emerging concept that physiological outcomes and mechanisms in different plant-virus interactions are far from unique (Aguilar et al., 2017).

\section{iv) Experimental procedures:}

\section{Plant growth conditions:}


Arabidopsis thaliana Col-0 and Ler ecotypes and mutant seeds were stratified at $4^{\circ} \mathrm{C}$ for 3 days and grown in a controlled environmental chamber (Conviron PGR14; Conviron, Winnipeg, Manitoba, Canada). For soil-based experiments, plants were grown in individual pots in trays and plants were well watered the day before measurements excluding drought experiments. For long days experiments, similar conditions as described by (Boyes et al., 2001) were used, with minor modifications: A 15.5 hours light/7.5 hours dark photoperiod with $\mathrm{T}\left({ }^{\circ} \mathrm{C}\right)=23 / 21, \mathrm{Hr}(\%)=60 / 65$, and a light intensity of $115(+/-10) \mu \mathrm{E} \mathrm{m} \mathrm{m}^{-2} \mathrm{~s}^{-1}$ was used; additionally, two continuous $1 / 2 \mathrm{~h}$ ramps for $\mathrm{T}, \mathrm{Hr}(\%)$ and light intensity were added to simulate dawn/nightfall. For short days experiments (including all hydroponics experiments) growing conditions were identical except for photoperiod $=10 / 14$. Except stated otherwise, all experiments were performed in short-days conditions. Hydroponic growth protocol, solutions and set-up were adapted from (Conn et al., 2013).

\section{Virus infection assays:}

TuMV-UK1 strain (accession number X65978) (Sánchez et al., 1998) and JPN1 strain (accession number KM094174) (Sánchez et al., 2015) were maintained in infected $A$. thaliana Col-0. Fresh sap was obtained immediately prior to use in order to inoculate plants with sodium sulfite buffer $\left(1 \% \mathrm{~K}_{2} \mathrm{HPO}_{4}+0.1 \% \mathrm{Na}_{2} \mathrm{SO}_{3}\right.$ [wt/vol]). ORMV (Aguilar et al., 1996) was maintained in Nicotiana tabacum (cv. Xhanti nn) and infective sap was obtained after grinding infected leaves with mortar and pestle in $50 \mathrm{mM}$ phosphate buffer $\mathrm{pH}=7.5$. Mockinoculated plants were rubbed with carborundum dust with either sodium sulfite buffer or 50 mM phosphate buffer $\mathrm{pH}=7.5$, respectively. Plants were mechanically inoculated at 1.08-1.09 growth stage (Boyes et al., 2001) in true leaves \#3 and \#4 at around 22-24 days post-sowing. These leaves were almost fully developed by the time of the procedure and therefore constituted a source tissue for the export of molecular signals and virions systemically, particularly to those leaves forming closer angles with the inoculated ones (Farmer et al., 2013; Manacorda et al., 2013). To allow for inter-experiment and inter-parameter comparison, all measurements were performed at the same stage of viral infection (11-13 DPI) except otherwise stated. DPI = Days postinoculation.

\section{Image acquisition:}

Infrared images were taken with an AVIO TVS-200P infrared camera (Nippon Avionics Co. Ltd., Japan) and analyzed with GORATEC software (CGORATEC Technology GmbH, Otto-Hahn-Strasse 21 D-85435, Erding, Germany). Infrared camera settings were adjusted according to the manufacturer's User Manual. In order to facilitate the manual segmentation of the rosette from the otherwise more heterogeneous background in soilbased experiments, the substrate was covered with a porous black cloth. Similar $\mathrm{T}_{\text {leaf }}$ increases were registered relative to the mock-inoculated controls in both experimental setups. In experiments where specimens were imaged at different days post-inoculation (DPI), photographs were taken at the same time of the day on successive days. The average rosette temperature per plant $\left(\mathrm{T}_{\text {leaf }}\right)$ was used for statistical analysis. Normalized $\Delta T_{\text {leaf }}$ between treatments was calculated setting average mock-inoculated rosette temperatures at 0 and then computing $\mathrm{T}_{\text {leaf }}$ differences for all individual plants. For overnight recording of infrared images, the infrared camera was placed standing on a tripod inside the growth chamber. Zenithal photographs of the tray containing hydroponically grown plants were taken at fixed intervals of time. Average rosette temperatures were obtained for each plant at each time point. A linear mixed model with treatment and time as fixed effects and plant as random effect was fitted to test for $T_{\text {leaf }}$ temperature differences between treatments along all the time points (Table S1) and periods of day (Table S2). An autoregressive-moving average model of 
order 1 (ARMA $(1,1))$ was found to be the best fit for both analyses. Visible-light images were taken with a Canon PowerShot SX50HS camera.

\section{Stomatal conductance and stomatal aperture analyses:}

Stomatal conductance $\left(g_{s}\right)$ measurements were performed with a SC-1 Leaf Porometer (METER Group, Inc. USA) following the manufacturer's Operator's Manual Version 8 recommendations regarding calibration and general use. $G_{s}$ was measured in the abaxial side of the middle part of leaf \#8 across all treatments and genotypes at $24-27.9{ }^{\circ} \mathrm{C}$ and $46.7-66.9 . \%$ relative humidity (range of conditions across experiments) around noon. Stomatal aperture was measured in the abaxial side of the middle part of leaf \#8 of infected or mocktreated plants. Two epidermal peels were used per leaf, and 20 stomata were randomly chosen for measurement in each peel. Peels were obtained using adhesive tape, and mounted for microscopic observation using a $10 \mathrm{mM} \mathrm{KCl} / 10 \mathrm{mM}$ MES-KOH, $\mathrm{pH}=6.15$ solution. Four or five plants were analyzed per experiment and two independent experiments were performed, showing similar results. For both Col-0 and abi2-1 data separate linear mixed effect models were applied, with treatment as fixed effect and individual (each one with $n=40$ stomatal apertures measured) as random effect after checking that Peel within Individual had a negligible effect.

\section{Rosette water loss experiments:}

For relative daily water consumption, hydroponically grown plants were separately moved at 12 DPI from trays to closed Falcon tubes containing fresh BNS and weighted on a precision scale. Weight differences were recorded after $24 \mathrm{~h}$. Rosette fresh weight (RFW) was measured to relativize water loss. Two independent experiments showing similar results were performed and the $P$-value $(P=0.0016)$ was calculated for the hierarchical ANOVA test of the linear model considering both experiments. For initial dehydration rate experiments, rosettes were detached at $12 \mathrm{DPI}$, imaged and placed on a precision scale (abaxial side upwards). Rosette weight loss was recorded every $15 \mathrm{~s}$ for $2 \mathrm{~min}$. Taking into account the time-dependency of the data (serial correlation of data arising from measurements taken on the same experimental unit several times), differences in losses in relative rosette weight per projected area ( $\operatorname{PrA}$ ) per time regarding treatments were assessed using generalized least squares models. A comparison between several models led to the selection of a general correlation structure with different inter-time variances allowed. Multiple comparison tests were used to detect specific time points when differences between treatments were present.

\section{Hormone quantification:}

Individual plants growing in pots were harvested at $12 \mathrm{DPI}$ and pooled within treatment (pool size $3 \leq \mathrm{N} \leq 11$ plants; five pools per treatment were used)). Plants were well-watered throughout the experiment and fully hydrated $20 \mathrm{~h}$ prior to harvest to avoid water status differences between treatments and to ensure no waterstress could affect hormone concentration determination. Systemic rosette tissue comprising leaves \#8 and upper were harvested and immediately frozen in $\mathrm{N}_{2}$ (I). Extraction and purification of endogenous hormones was performed as described in (Durgbanshi et al., 2005) and then, they were separated by reversed-phase HPLC, using an Alliance 2695 separation module (Waters; Milford, MA, USA) equipped with a Restek Roc C18 $3 \mu \mathrm{m}$ column $(100 \times 3.0 \mathrm{~mm})$. The identification and quantification of hormones was performed using a quadrupole tandem mass spectrometer (Quattro Ultima, Micromass; Manchester, UK) fitted with an negative electrospray ion (ESI') source, in multiple reactions monitoring mode (MRM). Source temperature was to $100^{\circ} \mathrm{C}$. The collision energies and cone voltage were set to $15 \mathrm{eV}$ and $35 \mathrm{~V}$. The MassLynx spectrometry software program, V. 4.1 (Waters) was used for data analysis. 
Two independent experiments showing similar results were performed and $p$-values were calculated for the hierarchical ANOVA test of the linear model considering both experiments.

\section{Hormone treatment:}

$\mathrm{SA}$ at $0.5 \mathrm{mM}(\mathrm{pH}=7)$ was sprayed on Col-0 plants grown under LD conditions at growth stage 1.08. Control plants were sprayed with the same volume of the same solution, without SA $(\mathrm{pH}=7)$. Effectiveness of treatment was confirmed by qRT-PCR using SA-inducible PR1 (AT2G14610) (Uknes et al., 1992). Samples were harvested at 4 or 24 hours post treatment (HPT) and processed as described in (Manacorda et al., 2013)

\section{qPCR assays:}

Oligonucleotide primer sets for real-time (quantitative) PCR were designed using Vector NTI Advance 9 software (Life Technologies, Carlsbad, CA, U.S.A.). They are listed in Table S5. Details on the minimum information for publication of quantitative real-time PCR experiments (MIQE Guidelines: (Bustin et al., 2009; Bustin et al., 2010) are listed in Table S6. Primers were designed to target exon regions and for genes for which splice variants are predicted using ThaleMine, primers were designed in order to target all splice variants. For qPCR analysis, LinRegPCR program (Ramakers et al., 2003) and the normalization method of (Pfaffl et al., 2002) were used. Relative expression ratios and statistical analysis were calculated using fgStatistics software (Di Rienzo, 2009).

\section{Drought experiments:}

Seeds were sown either in a one or two plant-per-pot scheme (Verslues et al., 2006). For each experiment, up to 24 pots were placed in a common tray. Treatments were randomly assigned to plants. In the one-plant-perpot experiments, pots were mixed to minimize location effects. In the two plants per pot scheme one plant was randomly selected for TuMV infection and the other one was left as healthy control. Plants were fully bottom-watered to reach homogeneous pot weight just prior to inoculation (therefore $0 \mathrm{DPI}=0 \mathrm{DAWW}$ ). Afterwards, watering was withheld and plants were periodically imaged and inspected for development of symptoms of water stress. Then, plants were fully rewatered once from the bottom and the number of surviving plants was recorded after 3-5 days. The same experimental protocol was used for both long- and short-day photoperiods.

\section{Statistical analysis:}

Unless otherwise specified, all statistical analyses were performed using R (RStudio Team, 2016; RCoreTeam, 2016). For all statistical analysis, significance was set as: $N S=P>0.05, *=P \leq 0.05, * *=P \leq 0.01$, and $* * *=P \leq$ 0.001 .

For data presenting nested (hierarchical) or serial correlation (time-dependency) structure, linear mixed effects models ( $/ \mathrm{me}$ ) and generalized least squares models $(\mathrm{g} / \mathrm{s})$ were implemented using the $n / m e$ package of $\mathrm{R}$ (Pinheiro et al., 2020), used as suggested in (Pinheiro and Bates, 2000) for constructing, validating, comparing and selecting models. Multiple comparison tests were performed using the emmeans package (Lenth, 2019). 


\section{(vii) Accession numbers:}

Arabidopsis mutants were in the Col-0 background except abi2-1 (Ler). Those of them that were not a kind gift of fellow researchers were obtained from the Arabidopsis Biological Resource Center (http://www.arabidopsis.org). The accession numbers for the genes of the mutant plants used in this article are as follows: SID2 (At4g39030), NPR1 (At1g64280), AOS (At5g42650), LOX1 (At1g55020), ABA3 (At1g16540), ABI2 (At5g57050).

\section{(viii) Acknowledgements:}

We thank Dr. Flora Sánchez and Dr. Fernando Ponz for the kind gift of ORMV and TuMV virus (JPN1 and UK1 strains), Dr. Fernando Carrari for the lending of the Leaf Porometer (Decagon/METER), Dr. Rocío Tognacca for abi2-1 seeds, Dr. Jean-Luc Montillet for lox1-1 seeds, Dr. Annie Marion-Poll for aba3-1 seeds, Lic. Pablo Cáceres for assistance in the use of the Genevestigator bioinformatics tool and technicians Agustín Montenegro, Matías Rodríguez and Ignacio Tévez for careful plant growth management.

\section{(ix) Short legends for Supporting Information:}

Figure S1. TuMV induces an increase in $\mathrm{T}_{\text {leaf }}$ in Arabidopsis thaliana Col-0. $(\boldsymbol{a}, \boldsymbol{b})$ Images showing typical rosette phenotypes triggered by TuMV (UK1 strain) at 15 DPI under (a) visible and (b) infrared light (false color image with scale to the right). Average rosette temperature displayed. Both images display two representative plants for both mock-inoculated (upper row) and TuMV-infected (lower row) plants.

Figure S2. TuMV induces similar phenotypes in hydroponics than in soil-based experiments and maintains reduced stomatal aperture during nighttime. (a) Hydroponics-grown plants display similar phenotypes than their soil-grown counterparts (15 DPI). (b) Infrared images were taken at several DPIs from 2-15 DPI, and separate t-tests were performed to assess $T_{\text {leaf }}$ differences between treatments. $\mathrm{N}=4$ and $\mathrm{n}=7$ for mock and TuMV groups, respectively. (c-e) Hydroponics-grown plants were imaged from prior to dusk to after dawn, encompassing measurements for the entire nighttime between 12-13 DPI. (c) Representative IR photograph showing the tray with the plants. Green circles = mock-inoculated plants. Violet circles = TuMV-infected plants. Black box = plants not used for IR quantitative analysis. (d-e) Hydroponics-grown plants were imaged from prior to dusk to after dawn, encompassing measurements for the entire nighttime between 12-13 DPI. (d) Line graph showing group average rosette temperatures across the experiment for both treatments. (e) Box and jitter plot showing the data grouped by time of the day corresponding to the photoperiod set in the growing chamber. Note the dusk/dawn ramp.

Table S1. ANOVA table showing the combined effect of treatment and time on $\mathrm{T}_{\text {leaf }}$ differences between hydroponics-grown plants.

Table S2. ANOVA table showing the combined effect of treatment and time of day (= "period") on $T_{\text {leaf }}$ differences between hydroponics-grown plants. 
Table S3. Average $\mathrm{T}_{\text {leaf }}$ and $\Delta \mathrm{T}_{\text {leaf }}$ between mock-inoculated and TuMV-infected plants during the different time of day (= "period") categories. $\Delta \mathrm{T}_{\text {leaf }}$ between treatments were found to be similar across different time of day $(P>0.05)$.

Figure S3. TuMV induces a decrease in $g_{s}$ in hydroponic growth conditions. $\mathrm{N}=8$ per group.

Figure S4. Effect of TuMV on stomatal conductance in mutants in genes related to hormone production and signaling. $G_{s}$ measurements were taken in 12-DPI infected mutant plants and compared with healthy controls. All assays included measurements in Col-0 plants (infected vs. control), as WT controls, which always showed the low $g_{s}$ phenotype under TuMV infection (not shown).

Figure S5. Reported expression pattern of $A B I 2$ in Arabidopsis. (a) Boxplots showing that $A B I 2$ is mostly expressed in guard cells, followed by root endodermis and senescent leaves. (b) Comparative expression of $A B I 2$ along 10 developmental stages (scatterplot). Note the overexpression in senescent tissues. ( $\boldsymbol{c}-\boldsymbol{d}$ ) ABA is the most important perturbation inducing $A B I 2$ expression, with ABA-triggering stresses as drought, osmotic and salt stress following suite. (e) In the roots, $\mathrm{NaCl}$ strongly induces $A B I 2$ overexpression. For (c), a heat map shows changes in gene expression levels of $A B I 2$ across different experimental conditions as illustrated by Genevestigator V3. The log ratio (base 2) of the signal intensity relating treatment conditions to control conditions is illustrated using the color scale. For (d-e), "Electronic fluorescent pictographs" of $A B I 2$ are illustrated using the Arabidopsis efP-Browser. Absolute signal intensities are illustrated using a color scale with low levels of expression colored yellow and high levels colored red.

Table S4. Comparative analysis between reported gene expression summarized from Genevestigator V3 bioinformatic tools (first 4 rows) and $q P C R$ results from this work ( $5^{\text {th }}$ to $7^{\text {th }}$ rows). Down-regulation of the genes analyzed in this work is shown in green for both main perturbations (stresses) reported by Genevestigator (first 2 rows) and qPCR results from this study ( $5^{\text {th }}$ to $7^{\text {th }}$ rows). Opposite pattern is shown in red. Non-significant differences found in this study are in gray. DR = Down-regulated; UR = Up-regulated; NS = Non-statistically significant changes in expression detected.

Figure S6. Drought experiments with one plant per pot. (a), (b) Line graphs showing the kinetic of water loss (Ln scale) for pots with one plant only either (a) separately or (b) smoothed conditional means by treatment. (a) Interrupted lines indicate death plants before the ending of the experiment. (b) Confidence intervals (95\%) are shadowed in gray. Starting from 18 DAWW, LnWeight differences between treatments were statistically significant $(0.01<p<0.0001)$.

Figure S7. SA application downregulates RD29A. QPCR analyses at 4 and 24 HPT (=hours post treatment). Bars $=\mathrm{SE} . \mathrm{N}=5$ per group.

Figure S8. ORMV, a phytovirus unrelated to TuMV, also increases rosette surface temperature. (a) Representative infrared image showing a mock-inoculated Arabidopsis Col-0 plant and three ORMV-infected plants exhibiting higher rosette surface temperature. (b) Box-plot graph showing $T_{\text {leaf }}$ difference between treatments. $\mathrm{N}=7$ mock and 9 ORMV plants were imaged. 
Table S5. List of oligonucleotide primers used in qPCR experiments.

Table S6. Minimum Information for Publication of Quantitative Real-Time PCR Experiments (MIQE

Guidelines).

\section{(x) References:}

Aguilar, E., Cutrona, C., Toro, F.J. del, et al. (2017) Virulence determines beneficial trade-offs in the response of virusinfected plants to drought via induction of salicylic acid. Plant. Cell Environ., 40, 2909-2930. Available at:

http://www.ncbi.nlm.nih.gov/pubmed/28718885 [Accessed August 26, 2019].

Aguilar, I., Sánchez, F., Martin, A.M., Martinez-herrera, D. and Ponz, F. (1996) Nucleotide sequence of Chinese rape mosaic virus (oilseed rape mosaic virus), a crucifer tobamovirus infectious on Arabidopsis thaliana. Plant Mol. Biol., 191-197.

Alazem, M., He, M.-H., Moffett, P. and Lin, N.-S. (2017) Abscisic Acid Induces Resistance against Bamboo Mosaic Virus through Argonaute 2 and 3. Plant Physiol., 174, 339-355. Available at:

http://www.plantphysiol.org/lookup/doi/10.1104/pp.16.00015.

Alazem, M., Kim, K.-H. and Lin, N.-S. (2019) Effects of Abscisic Acid and Salicylic Acid on Gene Expression in the Antiviral RNA Silencing Pathway in Arabidopsis. Int. J. Mol. Sci., 20. Available at:

http://www.ncbi.nlm.nih.gov/pubmed/31126102 [Accessed June 25, 2019].

Alazem, M., Lin, K.-Y. and Lin, N.-S. (2014) The Abscisic Acid Pathway Has Multifaceted Effects on the Accumulation of Bamboo mosaic virus. Mol. Plant-Microbe Interact., 27, 177-189. Available at:

http://apsjournals.apsnet.org/doi/10.1094/MPMI-08-13-0216-R.

Alazem, M. and Lin, N.-S. (2017) Antiviral Roles of Abscisic Acid in Plants. Front. Plant Sci., 8, 1-10. Available at: http://journal.frontiersin.org/article/10.3389/fpls.2017.01760/full.

Alazem, M. and Lin, N.S. (2015) Roles of plant hormones in the regulation of host-virus interactions. Mol. Plant Pathol., 16, $529-540$.

Alazem, M., Tseng, K.C., Chang, W.C., Seo, J.K. and Kim, K.H. (2018) Elements Involved in the Rsv3-Mediated Extreme Resistance against an Avirulent Strain of Soybean Mosaic Virus. Viruses, 10, 1-16.

Alazem, M., Widyasari, K. and Kim, K.H. (2019) An avirulent strain of soybean mosaic virus reverses the defensive effect of abscisic acid in a susceptible soybean cultivar. Viruses, 11, 1-14.

Aou-ouad, H. El, Pou, A., Tomás, M., Montero, R., Ribas-Carbo, M., Medrano, H. and Bota, J. (2017) Combined effect of virus infection and water stress on water flow and water economy in grapevines. Physiol. Plant., 160, 171-184. Available at: http://doi.wiley.com/10.1111/ppl.12541 [Accessed November 7, 2018].

Ascencio-Ibáñez, J.T., Sozzani, R., Lee, T.-J., Chu, T.-M., Wolfinger, R.D., Cella, R. and Hanley-Bowdoin, L. (2008) Global analysis of Arabidopsis gene expression uncovers a complex array of changes impacting pathogen response and cell cycle during geminivirus infection. Plant Physiol., 148, 436-54. Available at:

http://www.pubmedcentral.nih.gov/articlerender.fcgi?artid=2528102\&tool=pmcentrez\&rendertype=abstract [Accessed August 1, 2010].

Bazzini, A. a, Manacorda, C. a, Tohge, T., et al. (2011) Metabolic and miRNA Profiling of TMV Infected Plants Reveals Biphasic Temporal Changes. PLoS One, 6, e28466. Available at: http://www.ncbi.nlm.nih.gov/pubmed/22174812 [Accessed December 18, 2011].

Bergès, S.E., Vile, D., Vazquez-Rovere, C., Blanc, S., Yvon, M., Bédiée, A., Rolland, G., Dauzat, M. and Munster, M. van (2018) Interactions Between Drought and Plant Genotype Change Epidemiological Traits of Cauliflower mosaic 
bioRxiv preprint doi: https://doi.org/10.1101/2020.08.03.235234; this version posted August 4, 2020. The copyright holder for this preprint (which was not certified by peer review) is the author/funder, who has granted bioRxiv a license to display the preprint in perpetuity. It is made available under aCC-BY-NC-ND 4.0 International license.

virus. Front. Plant Sci., 9, 703. Available at: https://www.frontiersin.org/article/10.3389/fpls.2018.00703/full [Accessed August 17, 2018].

Bhattacharyya, D. and Chakraborty, S. (2018) Chloroplast: the Trojan horse in plant-virus interaction. Mol. Plant Pathol., 19, 504-518. Available at: http://doi.wiley.com/10.1111/mpp.12533 [Accessed June 9, 2020].

Boyes, D.C., Zayed, a M., Ascenzi, R., McCaskill, a J., Hoffman, N.E., Davis, K.R. and Görlach, J. (2001) Growth stagebased phenotypic analysis of Arabidopsis: a model for high throughput functional genomics in plants. Plant Cell, 13, 1499-510. Available at: http://www.pubmedcentral.nih.gov/articlerender.fcgi?artid=139543\&tool=pmcentrez\& rendertype=abstract.

Brenya, E., Trusov, Y., Dietzgen, R.G. and Botella, J.R. (2016) Heterotrimeric G-proteins facilitate resistance to plant pathogenic viruses in Arabidopsis thaliana (L.) Heynh. Plant Signal. Behav., 11, e1212798. Available at: http://www.ncbi.nlm.nih.gov/pubmed/27454415 [Accessed September 2, 2019].

Bustin, S. a, Beaulieu, J.-F., Huggett, J., Jaggi, R., Kibenge, F.S.B., Olsvik, P. a, Penning, L.C. and Toegel, S. (2010) MIQE précis: Practical implementation of minimum standard guidelines for fluorescence-based quantitative real-time PCR experiments. BMC Mol. Biol., 11, 74. Available at:

http://www.pubmedcentral.nih.gov/articlerender.fcgi?artid=2955025\&tool=pmcentrez\&rendertype=abstract.

Bustin, S. a, Benes, V., Garson, J. a, et al. (2009) The MIQE guidelines: minimum information for publication of quantitative real-time PCR experiments. Clin. Chem., 55, 611-22. Available at:

http://www.ncbi.nlm.nih.gov/pubmed/19246619 [Accessed October 25, 2012].

Caird, M.A., Richards, J.H. and Donovan, L.A. (2006) Nighttime Stomatal Conductance and Transpiration in C3 and C4 Plants. Plant Physiol., 143, 4-10. Available at: http://www.plantphysiol.org/cgi/doi/10.1104/pp.106.092940.

Carr, J.P., Donnelly, R., Tungadi, T., et al. (2018) Viral Manipulation of Plant Stress Responses and Host Interactions With Insects. Adv. Virus Res., 102, 177-197. Available at:

https://www.sciencedirect.com/science/article/pii/S0065352718300381?dgcid=raven_sd_recommender_email [Accessed March 6, 2019].

Casteel, C.L., Alwis, M. De, Bak, A., Dong, H., Whitham, S.A. and Jander, G. (2015) Disruption of Ethylene Responses by Turnip mosaic virus Mediates Suppression of Plant Defense against the Green Peach Aphid Vector. Plant Physiol., 169, 209-218. Available at: http://www.plantphysiol.org/content/169/1/209 [Accessed August 30, 2019].

Chaerle, L., Caeneghem, W. Van, Messens, E., Lambers, H., Montagu, M. Van and Straeten, D. Van Der (1999) Presymptomatic visualization of plant-virus interactions by thermography. Nat. Biotechnol., 17, 813-816.

Chaerle, L., Pineda, M., Romero-Aranda, R., Straeten, D. Van Der and Barón, M. (2006) Robotized thermal and chlorophyll fluorescence imaging of pepper mild mottle virus infection in Nicotiana benthamiana. Plant Cell Physiol., 47, 1323-36. Available at: http://www.ncbi.nlm.nih.gov/pubmed/16943218 [Accessed June 4, 2013].

Collum, T.D. and Culver, J.N. (2016) The impact of phytohormones on virus infection and disease. Curr. Opin. Virol., 17, 25-31. Available at: http://dx.doi.org/10.1016/j.coviro.2015.11.003.

Conn, S.J., Hocking, B., Dayod, M., et al. (2013) Protocol: optimising hydroponic growth systems for nutritional and physiological analysis of Arabidopsis thaliana and other plants. Plant Methods, 9, 4. Available at: http://www.pubmedcentral.nih.gov/articlerender.fcgi?artid=3610267\&tool=pmcentrez\&rendertype=abstract [Accessed September 2, 2014].

Conti, G., Rodriguez, M.C., Manacorda, C.A. and Asurmendi, S. (2012) Transgenic expression of tobacco mosaic virus capsid and movement proteins modulate plant basal defense and biotic stress responses in Nicotiana tabacum. Mol. Plant-Microbe Interact., 25, 1370-1384.

Costa, J.M., Grant, O.M. and Chaves, M.M. (2013) Thermography to explore plant-environment interactions. J. Exp. Bot., 64, 3937-3949. 
bioRxiv preprint doi: https://doi.org/10.1101/2020.08.03.235234; this version posted August 4, 2020. The copyright holder for this preprint (which was not certified by peer review) is the author/funder, who has granted bioRxiv a license to display the preprint in perpetuity. It is made available under aCC-BY-NC-ND 4.0 International license.

Dietrich, D., Pang, L., Kobayashi, A., et al. (2017) Root hydrotropism is controlled via a cortex-specific growth mechanism. Nat. Plants, 3.

Duan, L., Dietrich, D., Ng, C.H., Yeen Chan, P.M., Bhalerao, R., Bennett, M.J. and Dinneny, J.R. (2013) Endodermal ABA signaling promotes lateral root quiescence during salt stress in Arabidopsis seedlings. Plant Cell, 25, 324-341.

Durgbanshi, A., Arbona, V., Pozo, O., Miersch, O., Sancho, J. V. and Gómez-Cadenas, A. (2005) Simultaneous Determination of Multiple Phytohormones in Plant Extracts by Liquid Chromatography-Electrospray Tandem Mass Spectrometry. J. Agric. Food Chem., 53, 8437-8442. Available at: http://www.ncbi.nlm.nih.gov/pubmed/16248534 [Accessed October 27, 2019].

Durrant, W.E., Wang, S. and Dong, X. (2007) Arabidopsis SNI1 and RAD51D regulate both gene transcription and DNA recombination during the defense response. Proc. Natl. Acad. Sci. U. S. A., 104, 4223-4227. Available at: https://www.pnas.org/content/104/10/4223 [Accessed June 28, 2020].

Farmer, E., Farmer, E., Mousavi, S. and Lenglet, A. (2013) Leaf numbering for experiments on long distance signalling in Arabidopsis. Protoc. Exch. Available at: http://www.nature.com/protocolexchange/protocols/2787 [Accessed November 15, 2018].

Grimmer, M.K., John Foulkes, M. and Paveley, N.D. (2012) Foliar pathogenesis and plant water relations: a review. J. Exp. Bot., 63, 4321-4331. Available at: https://academic.oup.com/jxb/article-lookup/doi/10.1093/jxb/ers143 [Accessed November 7, 2018].

Gudesblat, G.E., Torres, P.S. and Vojnov, A.A. (2009) Xanthomonas campestris overcomes Arabidopsis stomatal innate immunity through a DSF cell-to-cell signal-regulated virulence factor. Plant Physiol., 149, 1017-1027.

Guo, D.-P., Guo, Y.-P., Zhao, J.-P., Liu, H., Peng, Y., Wang, Q.-M., Chen, J.-S. and Rao, G.-Z. (2005) Photosynthetic rate and chlorophyll fluorescence in leaves of stem mustard (Brassica juncea var. tsatsai) after turnip mosaic virus infection. Plant Sci., 168, 57-63. Available at:

https://www.sciencedirect.com/science/article/pii/S0168945204003334\#fig1 [Accessed July 16, 2018].

Hall, A.E. and Loomis, R.S. (1972) An Explanation for the Difference in Photosynthetic Capabilities of Healthy and Beet Yellows Virus-infected Sugar Beets (Beta vulgaris L.). Plant Physiol., 50, 576-80. Available at: http://www.ncbi.nlm.nih.gov/pubmed/16658220 [Accessed November 6, 2018].

Hickman, R., Mendes, M.P., Verk, M.C. Van, Dijken, A.J.H. Van, Sora, J. Di, Denby, K., Pieterse, C.M.J. and Wees, S.C.M. Van (2019) Transcriptional Dynamics of the Salicylic Acid Response and its Interplay with the Jasmonic Acid Pathway. bioRxiv, 742742. Available at: https://www.biorxiv.org/content/10.1101/742742v1 [Accessed August 27, 2019].

Hily, J.M., Poulicard, N., Mora, M.Á., Pagán, I. and García-Arenal, F. (2016) Environment and host genotype determine the outcome of a plant-virus interaction: From antagonism to mutualism. New Phytol., 209, 812-822.

Hruz, T., Laule, O., Szabo, G., Wessendorp, F., Bleuler, S., Oertle, L., Widmayer, P., Gruissem, W. and Zimmermann, P. (2008) Genevestigator v3: a reference expression database for the meta-analysis of transcriptomes. Adv.

Bioinformatics, 2008, 420747. Available at: http://www.ncbi.nlm.nih.gov/pubmed/19956698 [Accessed September 10, 2019].

Jeong, C.Y., Lee, S.A., Kang, C.-S., Cheong, Y.-K. and Lee, H. (2018) Overexpression of abiotic stress-induced AtMYBL-O results in negative modulation of abscisic acid signaling through the downregulation of abscisic acid-responsive genes in Arabidopsis thaliana. Plant Growth Regul., 84, 25-36. Available at: http://link.springer.com/10.1007/s10725-017-0318-8 [Accessed August 14, 2019].

Kang, J., Hwang, J.-U., Lee, M., Kim, Y.-Y., Assmann, S.M., Martinoia, E. and Lee, Y. (2010) PDR-type ABC transporter mediates cellular uptake of the phytohormone abscisic acid. Proc. Natl. Acad. Sci. U. S. A., 107, 2355-60. Available at: http://www.ncbi.nlm.nih.gov/pubmed/20133880 [Accessed December 4, 2019]. 
Klessig, D.F., Choi, H.W. and Dempsey, D.A. (2018) Systemic acquired resistance and salicylic acid: Past, present, and future. Mol. Plant-Microbe Interact., 31, 871-888.

Koornneef, M., Reuling, G. and Karssen, C.M. (1984) The isolation and characterization of abscisic acid-insensitive mutants of Arabidopsis thaliana. Physiol. Plant., 61, 377-383. Available at: http://doi.wiley.com/10.1111/j.13993054.1984.tb06343.x [Accessed October 9, 2019].

Krishnakumar, V., Hanlon, M.R., Contrino, S., et al. (2015) Araport: the Arabidopsis Information Portal. Nucleic Acids Res., 43, D1003-D1009. Available at: http://academic.oup.com/nar/article/43/D1/D1003/2439074/Araport-theArabidopsis-Information-Portal [Accessed September 9, 2019].

Kuromori, T., Miyaji, T., Yabuuchi, H., Shimizu, H., Sugimoto, E., Kamiya, A., Moriyama, Y. and Shinozaki, K. (2010) ABC transporter AtABCG25 is involved in abscisic acid transport and responses. Proc. Natl. Acad. Sci. U. S. A., 107, 23612366.

Kuromori, T., Seo, M. and Shinozaki, K. (2018) ABA Transport and Plant Water Stress Responses. Trends Plant Sci., 23, 513-522. Available at: http://dx.doi.org/10.1016/j.tplants.2018.04.001.

Kushiro, T., Okamoto, M., Nakabayashi, K., et al. (2004) The Arabidopsis cytochrome P450 CYP707A encodes ABA 8'hydroxylases: key enzymes in ABA catabolism. EMBO J., 23, 1647-56. Available at: http://www.ncbi.nlm.nih.gov/pubmed/15044947 [Accessed August 14, 2019].

Lasceve, G., Leymarie, J. and Vavasseur, a (1997) Alterations in light-induced stomatal opening in a starch- deficient mutant of Arabidopsis thaiiana L . deficient in chloroplast phosphoglucomutase activity. Environment, 20, 350-358.

Lee, S.C., Lim, C.W., Lan, W., He, K. and Luan, S. (2013) ABA signaling in guard cells entails a dynamic protein-protein interaction relay from the PYL-RCAR family receptors to ion channels. Mol. Plant, 6, 528-538. Available at: http://dx.doi.org/10.1093/mp/sss078.

Lee, S.Y., Boon, N.J., Webb, A.A.R. and Tanaka, R.J. (2016) Synergistic Activation of RD29A Via Integration of Salinity Stress and Abscisic Acid in Arabidopsis thaliana. Plant Cell Physiol., 57, 2147-2160. Available at: https://academic.oup.com/pcp/article/57/10/2147/2755877 [Accessed June 29, 2020].

Lenth, R. (2019) emmeans: Estimated Marginal Means, Aka 1.4.3.01., Least-Squares Means. R package version. Available at: https://cran.r-project.org/package=emmeans.

Leung, J., Merlot, S. and Giraudat, J. (1997) The arabidopsis ABSCISIC ACID-INSENSITIVE2 (ABI2) and ABI1 genes encode homologous protein phosphatases $2 \mathrm{C}$ involved in abscisic acid signal transduction. Plant Cell, 9, 759-771.

Lewsey, M.G. and Palukaitis, P. (2010) Signaling in Induced Resistance. Adv. Virus Res., 76, 57-121. Available at: https://www.sciencedirect.com/science/article/pii/S0065352710760036?via\%3Dihub [Accessed October 4, 2019].

Li, N., Han, X., Feng, D., Yuan, D. and Huang, L.J. (2019) Signaling crosstalk between salicylic acid and ethylene/Jasmonate in plant defense: Do we understand what they are whispering? Int. J. Mol. Sci., 20.

Li, W., Cui, X., Meng, Z., Huang, X., Xie, Q., Wu, H., Jin, H., Zhang, D. and Liang, W. (2012) Transcriptional Regulation of Arabidopsis MIR168a and ARGONAUTE1 Homeostasis in Abscisic Acid and Abiotic Stress Responses. Plant Physiol., 158, 1279-1292. Available at: http://www.plantphysiol.org/cgi/doi/10.1104/pp.111.188789.

Lim, C.W., Baek, W., Jung, J., Kim, J.-H.H. and Lee, S.C. (2015) Function of ABA in stomatal defense against biotic and drought stresses. Int. J. Mol. Sci., 16, 15251-15270. Available at: http://www.ncbi.nlm.nih.gov/pubmed/26154766 [Accessed September 10, 2019].

Lim, C.W. and Lee, S.C. (2015) Arabidopsis abscisic acid receptors play an important role in disease resistance. Plant Mol. Biol., 88, 313-324. Available at: http://www.ncbi.nlm.nih.gov/pubmed/25969135 [Accessed May 20, 2019].

Lindsey, D.W. and Gudauskas, R.T. (1975) Effects of Maize Dwarf Mosaic Virus in Water relations in Corn. 

available under aCC-BY-NC-ND 4.0 International license.

Phytopathology, 65, 434-440. Available at:

http://ci.nii.ac.jp/lognavi?name=nels\&lang=jp\&type=pdf\&id=ART0006437781.

Loebenstein, G. (2010) Plant Virus Diseases: Economic Aspects. In B. W. J. Mahy and M. H. V. van Regenmortel, eds. Desk encyclopedia of plant and fungal virology. San Diego, CA, USA: Elsevier Academic Press, pp. 426-430.

Ma, Y., Cao, J., He, J., Chen, Q., Li, X. and Yang, Y. (2018) Molecular Mechanism for the Regulation of ABA Homeostasis During Plant Development and Stress Responses. Int. J. Mol. Sci., 19. Available at: http://www.ncbi.nlm.nih.gov/pubmed/30463231 [Accessed June 10, 2019].

Mahalingam, R. (2015) Consideration of Combined Stress: A Crucial Paradigm for Improving Multiple Stress Tolerance in Plants. , 1-26.

Manacorda, C.A. and Asurmendi, S. (2018) Arabidopsis phenotyping through geometric morphometrics. Gigascience, 7. Available at: https://academic.oup.com/gigascience/article/doi/10.1093/gigascience/giy073/5039702 [Accessed September 3, 2018].

Manacorda, C.A., Mansilla, C., Debat, H.J., Zavallo, D., Sánchez, F., Ponz, F. and Asurmendi, S. (2013) Salicylic Acid Determines Differential Senescence Produced by Two Turnip mosaic virus Strains Involving Reactive Oxygen Species and Early Transcriptomic Changes. Mol. Plant. Microbe. Interact., 26, 1486-98. Available at: http://www.ncbi.nlm.nih.gov/pubmed/23945002.

Maruri-López, I., Aviles-Baltazar, N.Y., Buchala, A. and Serrano, M. (2019) Intra and Extracellular Journey of the Phytohormone Salicylic Acid. Front. Plant Sci., 10, 423. Available at: https://www.frontiersin.org/article/10.3389/fpls.2019.00423/full [Accessed August 27, 2019].

Matthews, R.E.F. (Richard E.F., Hull, R. and Matthews, R.E.F. (Richard E.F. (2002) Matthews' plant virology., Academic Press. Available at: http://www.sciencedirect.com/science/book/9780123611604 [Accessed August 14, 2017].

Melotto, M., Zhang, L., Oblessuc, P.R. and He, S.Y. (2017) Stomatal Defense a Decade Later. Plant Physiol., 174, 561571. Available at: http://www.plantphysiol.org/lookup/doi/10.1104/pp.16.01853.

Merilo, E., Jalakas, P., Laanemets, K., Mohammadi, O., Hõrak, H., Kollist, H. and Brosché, M. (2015) Abscisic Acid Transport and Homeostasis in the Context of Stomatal Regulation. Mol. Plant, 8, 1321-1333. Available at: https://www.sciencedirect.com/science/article/pii/S1674205215002695?dgcid=raven_sd_recommender_email [Accessed September 9, 2019].

Merilo, E., Yarmolinsky, D., Jalakas, P., Parik, H., Tulva, I., Rasulov, B., Kilk, K. and Kollist, H. (2017) Stomatal VPD response: there is more to the story than ABA. Plant Physiol., 176, pp.00912.2017. Available at: http://www.plantphysiol.org/lookup/doi/10.1104/pp.17.00912.

Merlot, S., Gosti, F., Guerrier, D., Vavasseur, A. and Giraudat, J. (2001) The ABI1 and ABI2 protein phosphatases 2C act in a negative feedback regulatory loop of the abscisic acid signalling pathway. Plant J., 25, 295-303.

Merlot, S., Mustilli, A.-C., Genty, B., North, H., Lefebvre, V., Sotta, B., Vavasseur, A. and Giraudat, J. (2002) Use of infrared thermal imaging to isolate Arabidopsis mutants defective in stomatal regulation. Plant J., 30, 601-9. Available at: http://www.ncbi.nlm.nih.gov/pubmed/12047634.

Montillet, J.-L., Leonhardt, N., Mondy, S., et al. (2013) An Abscisic Acid-Independent Oxylipin Pathway Controls Stomatal Closure and Immune Defense in Arabidopsis J. L. Dangl, ed. PLoS Biol., 11, e1001513. Available at: http://dx.plos.org/10.1371/journal.pbio.1001513 [Accessed December 4, 2017].

Murray, R.R., Emblow, M.S.M., Hetherington, A.M. and Foster, G.D. (2016) Plant virus infections control stomatal development. Sci. Rep., 6, 1-7. Available at: http://dx.doi.org/10.1038/srep34507.

Narusaka, Y., Nakashima, K., Shinwari, Z.K., Sakuma, Y., Furihata, T., Abe, H., Narusaka, M., Shinozaki, K. and Yamaguchi-Shinozaki, K. (2003) Interaction between two cis-acting elements, ABRE and DRE, in ABA-dependent 
bioRxiv preprint doi: https://doi.org/10.1101/2020.08.03.235234; this version posted August 4, 2020. The copyright holder for this preprint (which was not certified by peer review) is the author/funder, who has granted bioRxiv a license to display the preprint in perpetuity. It is made available under aCC-BY-NC-ND 4.0 International license.

expression of Arabidopsis rd29A gene in response to dehydration and high-salinity stresses. Plant J., 34, 137-148.

Okuma, E., Nozawa, R., Murata, Y. and Miura, K. (2014) Accumulation of endogenous salicylic acid confers drought tolerance to Arabidopsis. Plant Signal. Behav., 9, e28085. Available at:

http://www.ncbi.nlm.nih.gov/pubmed/24603484 [Accessed October 4, 2019].

Orman-Ligeza, B., Morris, E.C., Parizot, B., et al. (2018) The Xerobranching Response Represses Lateral Root Formation When Roots Are Not in Contact with Water. Curr. Biol., 28, 3165-3173.e5. Available at: http://www.ncbi.nlm.nih.gov/pubmed/30270188 [Accessed October 11, 2019].

Park, J., Lee, Y., Martinoia, E. and Geisler, M. (2017) Plant hormone transporters: what we know and what we would like to know. BMC Biol., 15, 93. Available at: http://bmcbiol.biomedcentral.com/articles/10.1186/s12915-0170443-x [Accessed September 9, 2019].

Pasin, F., Shan, H., García, B., et al. (2020) Journal Pre-proof Abscisic acid connects phytohormone signaling with RNA metabolic pathways and promotes an antiviral response that is evaded by a self-controlled RNA virus. PLANT Commun., 100099. Available at: https://doi.org/10.1016/j.xplc.2020.100099 [Accessed July 14, 2020].

Pesti, R., Kontra, L., Paul, K., Vass, I., Csorba, T., Havelda, Z. and Várallyay, É. (2019) Differential gene expression and physiological changes during acute or persistent plant virus interactions may contribute to viral symptom differences S.-M. Wong, ed. PLoS One, 14, e0216618. Available at: http://dx.plos.org/10.1371/journal.pone.0216618 [Accessed May 10, 2019].

Pfaffl, M.W., Horgan, G.W. and Dempfle, L. (2002) Relative expression software tool (REST) for group-wise comparison and statistical analysis of relative expression results in real-time PCR. Nucleic Acids Res., 30, e36. Available at: http://www.ncbi.nlm.nih.gov/pubmed/11972351 [Accessed November 8, 2018].

Pieterse, C.M.J., Does, D. Van der, Zamioudis, C., Leon-Reyes, A. and Wees, S.C.M. Van (2012) Hormonal Modulation of Plant Immunity. Annu. Rev. Cell Dev. Biol., 28, 489-521. Available at: http://www.annualreviews.org/doi/10.1146/annurev-cellbio-092910-154055 [Accessed August 27, 2019].

Pinheiro, J., Bates, D., DebRoy, S. and Sarkar, D. (2020) _nlme: Linear and Nonlinear Mixed Effects Models_. R package version 3.1-144.

Pinheiro, J.C. and Bates, D.M. (2000) Mixed-Effects Models in S and S-PLUS J. Chambers, W. Eddy, and W. Hardle, eds., New York: Springer-Verlag. Available at: http://link.springer.com/10.1007/0-387-22747-4_1.

Poque, S., Wu, H.-W., Huang, C.-H., Cheng, H.-W., Hu, W.-C., Yang, J.-Y., Wang, D. and Yeh, S.-D. (2018) Potyviral GeneSilencing Suppressor HCPro Interacts with Salicylic Acid (SA)-Binding Protein 3 to Weaken SA-Mediated Defense Responses. Mol. Plant-Microbe Interact., 31, 86-100. Available at:

https://apsjournals.apsnet.org/doi/10.1094/MPMI-06-17-0128-FI [Accessed January 22, 2019].

Prasch, C.M. and Sonnewald, U. (2013) Simultaneous application of heat, drought, and virus to Arabidopsis plants reveals significant shifts in signaling networks. Plant Physiol., 162, 1849-66. Available at: http://www.ncbi.nlm.nih.gov/pubmed/23753177 [Accessed August 29, 2019].

Ramakers, C., Ruijter, J.M., Deprez, R.H.L. and Moorman, A.F.. (2003) Assumption-free analysis of quantitative realtime polymerase chain reaction (PCR) data. Neurosci. Lett., 339, 62-66. Available at: https://www.sciencedirect.com/science/article/pii/S0304394002014234?via\%3Dihub [Accessed November 8, 2018].

Ramegowda, V. and Senthil-Kumar, M. (2015) The interactive effects of simultaneous biotic and abiotic stresses on plants: Mechanistic understanding from drought and pathogen combination. J. Plant Physiol., 176, 47-54.

Raskin, I. (1992) Role of Salicylic Acid in Plants. Annu. Rev. Plant Physiol. Plant Mol. Biol., 43, 439-463. Available at: http://www.annualreviews.org/doi/10.1146/annurev.pp.43.060192.002255 [Accessed August 27, 2019]. 
Rauf, M., Arif, M., Dortay, H., Matallana-Ramírez, L.P., Waters, M.T., Gil Nam, H., Lim, P.-O., Mueller-Roeber, B. and Balazadeh, S. (2013) ORE1 balances leaf senescence against maintenance by antagonizing G2-like-mediated transcription. EMBO Rep., 14, 382-8. Available at: http://www.ncbi.nlm.nih.gov/pubmed/23459204 [Accessed December 30, 2013].

RCoreTeam (2016) R: A language and environment for statistical computing. Available at: https://www.r-project.org/.

Revers, F. and García, J.A. (2015) Molecular biology of potyviruses 1st ed., Elsevier Inc. Available at: http://dx.doi.org/10.1016/bs.aivir.2014.11.006.

Rienzo, J.A. Di (2009) fgStatistics. Statistical software for the analysis of microarray data. Available at: http://sites.google.com/site/fgstatistics.

Rodriguez, M.C., Conti, G., Zavallo, D., Manacorda, C.A. and Asurmendi, S. (2014) TMV-Cg Coat Protein stabilizes DELLA proteins and in turn negatively modulates salicylic acid-mediated defense pathway during Arabidopsis thalianaviral infection. BMC Plant Biol., 14, 210. Available at: http://bmcplantbiol.biomedcentral.com/articles/10.1186/s12870014-0210-x [Accessed December 2, 2019].

Rodriguez, P.L., Lozano-Juste, J. and Albert, A. (2019) PYR/PYL/RCAR ABA receptors, Elsevier Ltd. Available at: https://doi.org/10.1016/bs.abr.2019.05.003.

RStudio Team (2016) RStudio: Integrated Development for R. Available at: http://www.rstudio.com/.

Ryan, F.P. (2004) Human endogenous retroviruses in health and disease: a symbiotic perspective. J. R. Soc. Med., 97, 560-5. Available at: http://www.ncbi.nlm.nih.gov/pubmed/15574851 [Accessed November 2, 2018].

Sánchez, F., Manrique, P., Mansilla, C., et al. (2015) Viral Strain-Specific Differential Alterations in Arabidopsis Developmental Patterns. Mol. Plant-Microbe Interact., 28, 1304-1315.

Sánchez, F., Martínez-Herrera, D., Aguilar, I. and Ponz, F. (1998) Infectivity of turnip mosaic potyvirus cDNA clones and transcripts on the systemic host Arabidopsis thaliana and local lesion hosts. Virus Res., 55, 207-19. Available at: http://www.ncbi.nlm.nih.gov/pubmed/9725673.

Tan, B.-C., Joseph, L.M., Deng, W.-T., Liu, L., Li, Q.-B., Cline, K. and McCarty, D.R. (2003) Molecular characterization of the Arabidopsis 9 -cis epoxycarotenoid dioxygenase gene family. Plant J., 35, 44-56. Available at: http://doi.wiley.com/10.1046/j.1365-313X.2003.01786.x [Accessed June 10, 2019].

Uknes, S., Mauch-mani, B., Moyer, M., et al. (1992) Acquired Resistance in Arabidopsis. , 4, 645-656.

Verslues, P.E., Agarwal, M., Katiyar-Agarwal, S., Zhu, J. and Zhu, J.K. (2006) Methods and concepts in quantifying resistance to drought, salt and freezing, abiotic stresses that affect plant water status. Plant J., 45, 523-539.

Vishwakarma, K., Upadhyay, N., Kumar, N., et al. (2017) Abscisic Acid Signaling and Abiotic Stress Tolerance in Plants: A Review on Current Knowledge and Future Prospects. Front. Plant Sci., 8, 161. Available at: http://www.ncbi.nlm.nih.gov/pubmed/28265276 [Accessed August 27, 2019].

Vlad, F., Rubio, S., Rodrigues, A., et al. (2009) Protein phosphatases 2C regulate the activation of the Snf1-related kinase OST1 by abscisic acid in Arabidopsis. Plant Cell, 21, 3170-3184.

Vlot, A.C., Dempsey, D.M.A. and Klessig, D.F. (2009) Salicylic Acid, a Multifaceted Hormone to Combat Disease. Annu. Rev. Phytopathol.

Walsh, J.A. and Jenner, C.E. (2002) Turnip mosaic virus and the quest for durable resistance. Mol. Plant Pathol., 3, 289300. Available at: http://www.ncbi.nlm.nih.gov/pubmed/20569337 [Accessed August 30, 2019].

Wang, S.-D., Zhu, F., Yuan, S., et al. (2011) The roles of ascorbic acid and glutathione in symptom alleviation to SAdeficient plants infected with RNA viruses. Planta, 234, 171-81. Available at: 
bioRxiv preprint doi: https://doi.org/10.1101/2020.08.03.235234; this version posted August 4, 2020. The copyright holder for this preprint (which was not certified by peer review) is the author/funder, who has granted bioRxiv a license to display the preprint in perpetuity. It is made available under aCC-BY-NC-ND 4.0 International license.

http://www.ncbi.nlm.nih.gov/pubmed/21394469 [Accessed June 4, 2013].

Wang, S., Durrant, W.E., Song, J., Spivey, N.W. and Dong, X. (2010) Arabidopsis BRCA2 and RAD51 proteins are specifically involved in defense gene transcription during plant immune responses. Proc. Natl. Acad. Sci. U. S. A., 107, 22716-22721. Available at: https://www.pnas.org/content/107/52/22716 [Accessed June 28, 2020].

Wang, X., Wang, Y., Wang, L., et al. (2018) Arabidopsis PCaP2 Functions as a Linker Between ABA and SA Signals in Plant Water Deficit Tolerance. Front. Plant Sci., 9, 578. Available at: https://www.frontiersin.org/article/10.3389/fpls.2018.00578/full [Accessed January 17, 2019].

Westwood, J.H., Mccann, L., Naish, M., et al. (2013) A viral RNA silencing suppressor interferes with abscisic acidmediated signalling and induces drought tolerance in Arabidopsis thaliana. Mol. Plant Pathol., 14, 158-170.

Whenham, R.J., Fraser, R.S.S., Brown, L.P. and Payne, J.A. (1986) Tobacco-mosaic-virus-induced increase in abscisicacid concentration in tobacco leaves: Planta, 168, 592-598. Available at: http://link.springer.com/10.1007/BF00392281 [Accessed November 7, 2018].

Winter, D., Vinegar, B., Nahal, H., Ammar, R., Wilson, G. V. and Provart, N.J. (2007) An "Electronic Fluorescent Pictograph" Browser for Exploring and Analyzing Large-Scale Biological Data Sets I. Baxter, ed. PLoS One, 2, e718. Available at: https://dx.plos.org/10.1371/journal.pone.0000718 [Accessed September 10, 2019].

Xu, P., Chen, F., Mannas, J.P., Feldman, T., Sumner, L.W. and Roossinck, M.J. (2008) Virus infection improves drought tolerance. New Phytol., 180, 911-921. Available at: http://doi.wiley.com/10.1111/j.1469-8137.2008.02627.x [Accessed November 2, 2018].

Yamaguchi-Shinozaki, K. and Shinozaki, K. (1994) A novel cis-acting element in an Arabidopsis gene is involved in responsiveness to drought, low-temperature, or high-salt stress. Plant Cell, 6, 251-264. Available at: http://www.ncbi.nlm.nih.gov/pubmed/8148648 [Accessed December 3, 2019].

Yang, C., Guo, R., Jie, F., Nettleton, D., Peng, J., Carr, T., Yeakley, J.M., Fan, J.-B. and Whitham, S. a (2007) Spatial analysis of arabidopsis thaliana gene expression in response to Turnip mosaic virus infection. Mol. Plant. Microbe. Interact., 20, 358-70. Available at: http://www.ncbi.nlm.nih.gov/pubmed/17427806.

Yoshida, T., Christmann, A., Yamaguchi-Shinozaki, K., Grill, E. and Fernie, A.R. (2019) Revisiting the Basal Role of ABA Roles Outside of Stress. Trends Plant Sci., 24, 625-635. Available at: https://doi.org/10.1016/j.tplants.2019.04.008.

Zhao, J., Zhang, X., Hong, Y. and Liu, Y. (2016) Chloroplast in Plant-Virus Interaction. Front. Microbiol., 7, 1565. Available at: http://journal.frontiersin.org/article/10.3389/fmicb.2016.01565 [Accessed October 10, 2019]. 


\section{(xi) Tables}

Table 1

\begin{tabular}{cccccc|}
\hline Condition & & Mock & TuMv & $\begin{array}{c}\text { Adjusted } \\
\text { residuals: }\end{array}$ & $\boldsymbol{\chi}^{2}$ test (Fisher's exact) \\
\hline LD & Alive & 23 & 17 & 2,6268 & $\mathbf{0 , 0 2 1 5 5 4}$ \\
LD & Dead & 0 & 6 & & \\
\hline SD & Alive & 23 & 2 & 6,2161 & $\mathbf{7 , 2 8 7 4 E - 1 1}$ \\
SD & Dead & 0 & 21 & &
\end{tabular}

\section{(xii) Figure legends:}

Figure 1. Both JPN1 and UK1 TuMV strains similarly increase $T_{\text {leaf }}$ and reduce stomatal conductance in Arabidopsis. (a) Representative phenotypes of mock-inoculated controls (to the left) and TuMV (UK1)-infected (to the right) in plants growing in soil covered by breathable cloth at $12 \mathrm{DPI}$. (b) Representative thermal image (false-color scale to the right) showing $T_{\text {leaf }}$ (average rosette temperature) in TuMV (UK1) and mock plants. (c) $\Delta T_{\text {leaf }}$ normalized data of TuMV JPN1 and UK1 ( $5 \leq n \leq 9$ per group). Asterisks indicate statistically significant differences relative to the controls. (d) $G_{s}$ values for both TuMV strains (JPN1 and UK1) and mock plants (boxand-jitter plot). Tukey's multiple comparisons test. $8 \leq n \leq 13$ per group.

Figure 2. TuMV decreases stomatal aperture in systemic Col-0 leaves. Stomatal aperture in control and TuMV-infected plants at 12 DPI. Violin plots show 0.05, 0.5 and 0.95 quantiles for stomatal aperture data $(n=$ 40) from each individual. Data from two independent experiments showed similar results. Results of one representative experiment are shown, $n=5$ for each treatment group.

Figure 3. TuMV infection reduces relative water consumption. (a) Daily water consumption in TuMVinfected and mock-inoculated intact plants (12-13 DPI). RFW = Rosette Fresh Weight. Two independent experiments showing similar results were performed; combined results of both experiments are shown. $\mathrm{N}=4$ 6 for each treatment and group. (b-c) Initial dehydration rate experiments. Rosette weight loss recorded through time per rosette projected area. Two independent experiments were performed showing similar results. Results from one representative experiment are shown, $\mathrm{n}=8$ for each treatment group. Spaghetti plots show (b) all rosettes separately and (c) smoothed conditional means by treatment (confidence intervals (95\%) are shadowed in grey). Asterisks indicate statistically significant differences along time points.

Figure 4. TuMV infection increased $A B A$ and $S A$ concentration. Accumulation of $A B A, S A$ and JA were measured in the rosette of control and TuMV-infected plants. $N=5$ per treatment group. Data from two independent experiments showed similar results. Results from one representative experiment is shown.

Figure 5. The ABA-insensitive abi2-1 mutant abolishes TuMV-induced stomatal closure and exhibits a slight phenotype reversion. (a) $\boldsymbol{G}_{s}$ in abi2-1 control and TuMV-infected plants at $12 \mathrm{DPI}$. $\mathrm{N}=8$ for mock and $\mathrm{n}=16$ for TuMV. (b) Stomatal aperture in abi2-1 control and TuMV-infected plants at 12 DPI. Violin plots show 0.05, 
0.5 and 0.95 quantiles for stomatal aperture data $(n=40)$ from each individual. Data from two independent experiments showed similar results. Results from one representative experiment is shown, $\mathrm{n}=5$ for each treatment group, $\mathrm{p}>0.05$. Ler control plants showed the same $g_{s}$ response to TuMV infection as Col-0 (data not shown).

Figure 6. TuMV infection alters relative transcript accumulation of key genes in ABA metabolism and function. QPCR analyses of genes involved in ABA biosynthesis (a), catabolism (b), signaling (c), transport (d), and stress response (e). Bars = SE. $N \geq 4$ per group.

Figure 7. TuMV infection increases drought susceptibility in Arabidopsis. (a-b) Images showing plants at 26 DPI and DAWW and just prior re-watering (a) and 5 days after re-watering (b). Plant were grown in short day conditions. Mock-inoculated plants are placed at top for each pot, TuMV-infected plants next to them. (c-d) Comparison between drought experiments in short day (SD) and long day (LD) conditions. Line graphs show the kinetics of water loss (LnWeight) for pots containing two plants each, either in SD or LD conditions. Line graphs show each pot (c) separately and (d) smoothed conditional means by treatment (confidence intervals (95\%) are shadowed in grey). Two independent experiments rendered similar results. Results of one representative experiment are shown. (e) RD29A relative expression under TuMV infection in well watered LD conditions.

Table 1. Chi-square tests for LD and SD experiments showing reduced Arabidopsis tolerance to drought under TuMV infection. One representative experiment is shown. 
c)

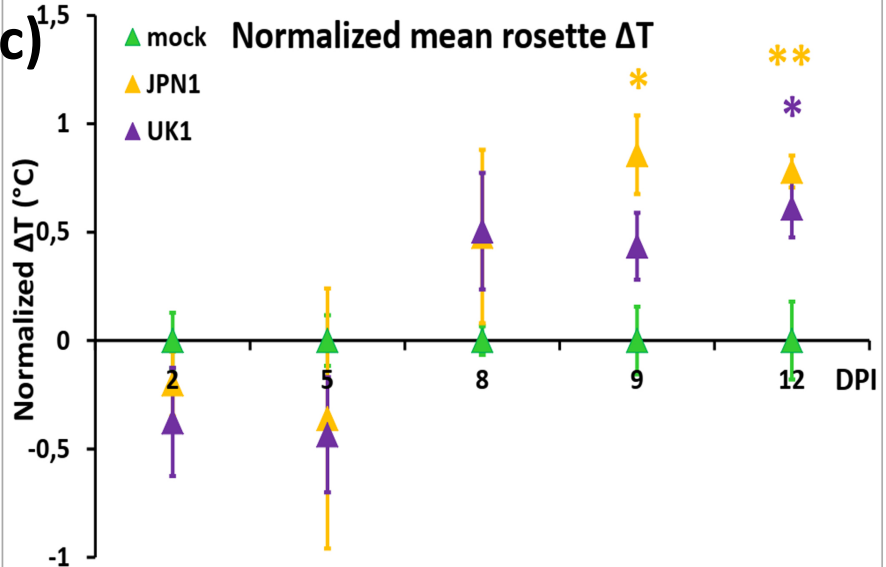

d)

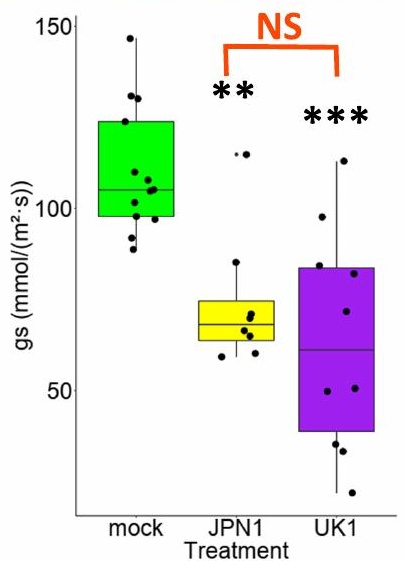




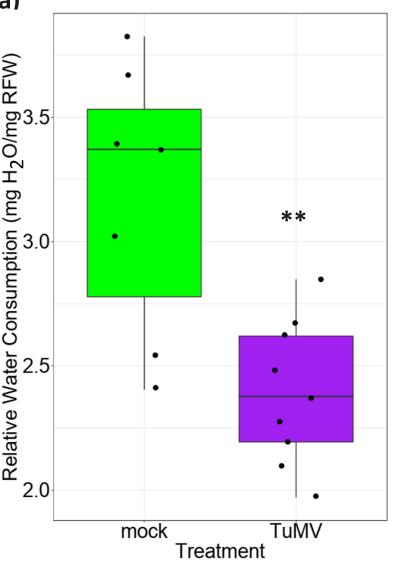

b)

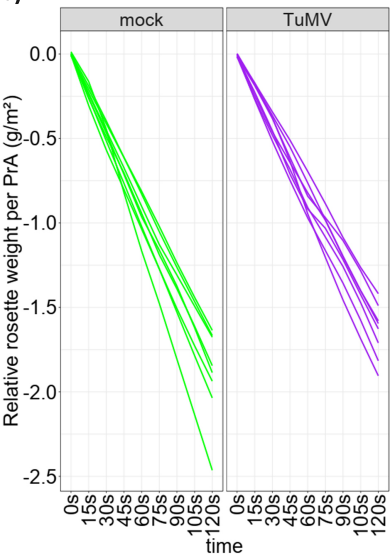

c)

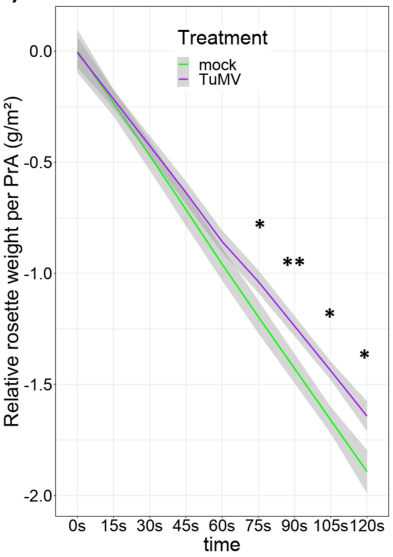




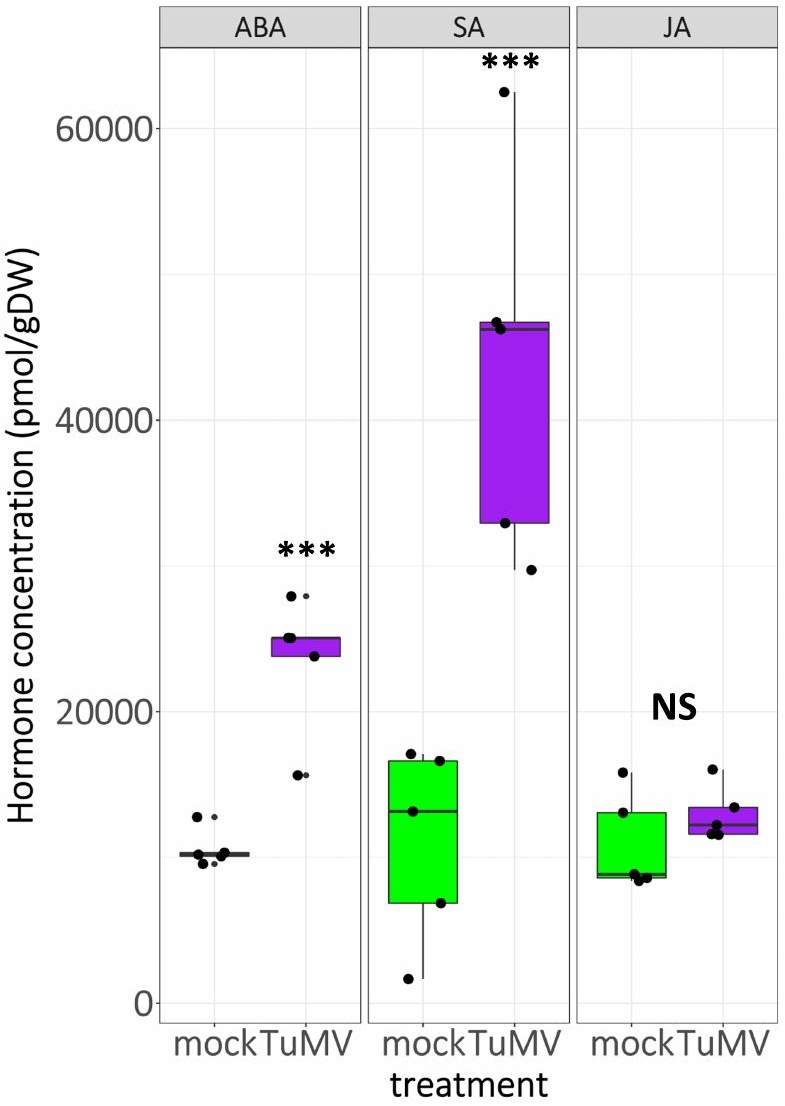




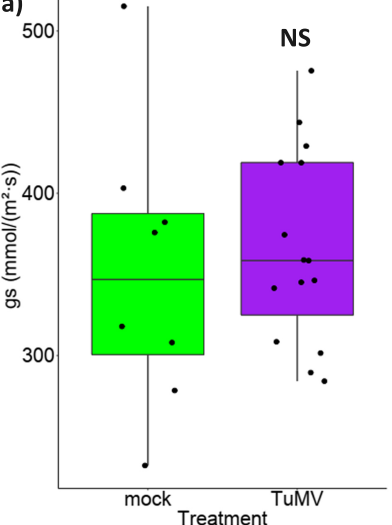

b) 8

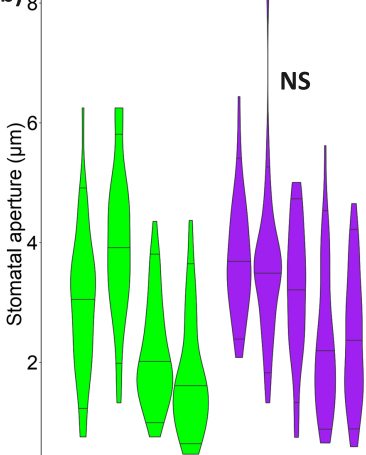

TuMV

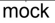

Treatment a)

Treatment 
a)

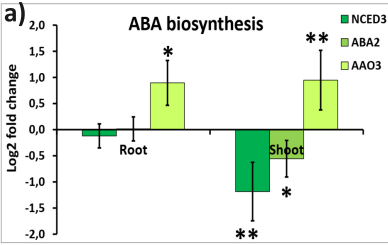

c)

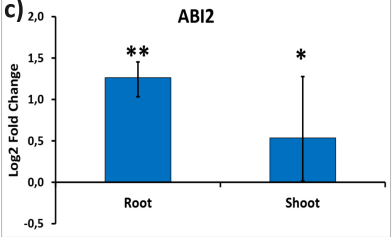

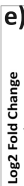

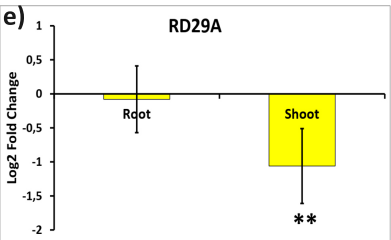

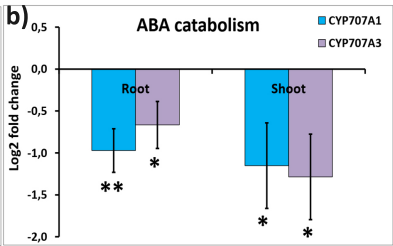

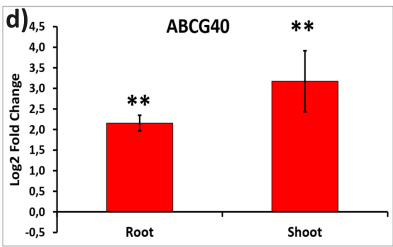


